\title{
Churn, Baby, Churn: Strategic Dynamics Among Dominant and Fringe Firms in a Segmented Industry
}

\author{
John M. de Figueiredo \\ Anderson Graduate School of Management, University of California at Los Angeles, 110 Westwood Plaza, Suite D508, \\ Los Angeles, California 90095-1481, jdefig@ucla.edu
}

Brian S. Silverman

Rotman School of Management, University of Toronto, 105 St. George Street, Toronto, Ontario, Canada M5S 3E6, silverman@rotman.utoronto.ca

\begin{abstract}
$T_{d}^{\text {h }}$ his paper integrates and extends the literatures on industry evolution and dominant firms to develop a dynamic theory of dominant and fringe competitive interaction in a segmented industry. It argues that a dominant firm, seeing contraction of growth in its current segment(s), enters new segments in which it can exploit its technological strengths, but that are sufficiently distant to avoid cannibalization. The dominant firm acts as a low-cost Stackelberg leader, driving down prices and triggering a sales takeoff in the new segment. We identify a "churn" effect associated with dominant firm entry: fringe firms that precede the dominant firm into the segment tend to exit the segment, while new fringe firms enter, causing a net increase in the number of firms in the segment. As the segment matures and sales decline in the segment, the process repeats itself. We examine the predictions of the theory with a study of price, quantity, entry, and exit across 24 product classes in the desktop laser printer industry from 1984 to 1996. Using descriptive statistics, hazard rate models, and panel data methods, we find empirical support for the theoretical predictions.
\end{abstract}

Key words: competitive dynamics; industry evolution; dominant firms

History: Accepted by Bruno Cassiman and Pankaj Ghemawat, special issue editors; received February 20,

2006. This paper was with the authors 3 months for 1 revision.

\section{Introduction}

The literature on industry evolution finds that the number of firms in an industry increases to a peak and then declines to a roughly steady-state number. This pattern has been attributed to competition and legitimation (Hannan and Freeman 1989), different cost structures of entrants and incumbents (Jovanovic and MacDonald 1994), and the technological prowess of incumbents relative to entrants (Klepper 2002). Recent research that has analyzed this pattern with more detailed data has noted a "sales takeoff" accompanying the increase in the number of firms in the industry. This has generally been attributed to the entry of firms with a lower (marginal) cost position. These firms shift the supply curve down and consequently cause the quantity of goods sold to increase (Bass 1980, Stoneman and Ireland 1983, Gort and Klepper 1982, Goldner and Tellis 1997). More recent work has argued that the sales takeoff is due not only to a shift in the supply curve, but also to an outward shift in the demand curve (Agarwal and Bayus 2002).

While these outcomes have been well documented (Gort and Klepper 1982, Agarwal and Gort 2002), the analysis of the causal mechanisms remains somewhat incomplete. Because data are usually aggregated at a high level in cross-industry studies focusing on industry-level dynamics, the current literature has not been able to identify one of the key causal mechanisms for a sales takeoff: entry or expansion by a dominant firm. Similarly, this industry-level focus, which assumes homogeneity in industry demand, has precluded study of the evolution of segments within an industry. ${ }^{1}$

This paper extends the industry evolution literature by developing a theory of the evolution of segmented industries, an area in which there is very little extant theory. A dominant firm expands within its existing segment until growth in that segment slackens. This causes the firm to selectively enter new segments in which it can exploit its technological capabilities but avoid cannibalization of its current products. The dominant firm acts as a Stackelberg leader, triggering a price decline, sales takeoff, and change in the pattern of entry and exit by fringe firms in that segment.

\footnotetext{
${ }^{1}$ The organizational ecology literature has studied density dependence in niches within a population. However, this is primarily viewed through the lens of legitimation and competition, rather than through the economic dynamics of industry evolution.
} 
This dynamic cycle repeats itself when growth in the new segment falls. To test the predictions of the theory, we adopt a novel empirical approach to explore dominant firm entry and its consequences for fringe firms. We study a single industry-the desktop laser printer industry - that is composed of several identifiable market segments. By studying the entry of the same dominant firm into different segments at different points in time, we are able to conduct multiple "experiments" while holding basic features of the industry and the players constant.

Our paper integrates economic and management theory on industry evolution to make three contributions to the literature. First, rather than examine dynamics at the aggregate industry level, our work examines how an industry evolves in different segments, and to what extent the theoretical predictions and empirical regularities found in the aforementioned literature inform the way in which segments develop in an industry. The evolution of multiple segments allows relationships between related segments to be considered through panel-data methods, and also allows us to extend theory to a more fine-grained level than this literature has previously considered.

Second, using segment-level microdata that have not been employed before in studies of this type, we shine new light on stylized facts from the industry evolution and dominant firm literatures. We show that the simultaneous or delayed correlation between entry and sales found in other studies is not due solely to the entry of fringe firms moving the supply curve or shifting demand. Rather, the entry of the dominant firm alters supply and demand leading to price declines and the sales takeoff. The strategic selection of segments by the dominant firm can have a significant effect on whether a sales takeoff occurs. With respect to the literature on the dominant firm, theoretical models typically begin with the formation of such a firm, and explore theoretically or empirically how such a firm defends its position by applying dynamic limit pricing to manage the tradeoff between high current profits and increased future competition (Kamien and Schwartz 1971, Caves et al. 1984). In this sense, the literature is static and usually considers the dominant firm solely in a defensive posture. Integrating these literatures with a comprehensive data set on the laser printer industry allows us to provide a much more complete picture of the sales takeoff, dominant firm behavior, and industry evolution.

Third, this paper explores the behavior and heterogeneity of fringe firms. We show that once the dominant firm enters, a swarm of fringe firms follows the dominant firm in, most likely in expectation of the sales takeoff. At the same time, fringe firms that precede the dominant firm into the segment tend to exit after dominant firm entry. This suggests that some fringe firms develop strategies, structures, and capabilities suitable for success in the presence of a dominant firm-perhaps entailing a low-cost structure and an ability to take advantage of positive externalities created by the dominant firm-while other fringe firms configure their resources to succeed in the selection environment that exists before entry of a dominant firm. It is the entry and exit decisions by small firms before, during, and after dominant firm entry that causes a large amount of "churn" in the segment, with both entry and exit rates increasing with arrival of the dominant firm. Many of the exiting firms move to new segments, which the dominant firm may subsequently enter, thus leading to a churning of the same firms once again.

We conduct our empirical examination of the theoretical predictions using data on the desktop laser printer industry from 1984 to 1996. Hewlett-Packard (HP) pioneered this industry in 1984, maintained at least $45 \%$ market share through 1996, and was widely perceived as the dominant player (de Figueiredo and Kyle 2005). We find empirical support for most of our theoretical predictions. In particular, we show that HP enters new segments when sales in its current segments stagnate or decline. The new segments that HP enters are related to HP's existing segments, in a manner suggesting that HP can exploit its existing technological capabilities in them (consistent with Klepper 2002). However, HP tends to avoid segments that are adjacent to its current segments in favor of segments further away, as long as such segments exist (consistent with Katz 1984). Furthermore, HP's entry is positively associated with a substantial price decline and a dramatic sales increase in a segment. Our evidence indicates that the dominant firm's entry triggers these changes in the segment. Finally, HP's entry precipitates a churning of fringe firms-increased entry rates following HP's entry, and increased exit rates for firms that entered the segment before HP entered. Although this study does not explore in detail the specific characteristics of fringe firms that encourage entry versus exit upon the entry of a dominant firm, we hope that it will encourage further work in this area. More broadly, we hope that this study will open up new avenues of research on the strategic dynamics in segmented industries and on dominant firm-fringe firm interactions.

\section{Theoretical Development and Framework}

\subsection{Preliminaries: Definition of the Dominant Firm and Summary of Theory}

In theoretical treatments of dominant firm behavior, dominance is defined by two characteristics: possession of a cost advantage and ability to price as a 
Figure 1 Dynamic Cycle in a Segmented Industry

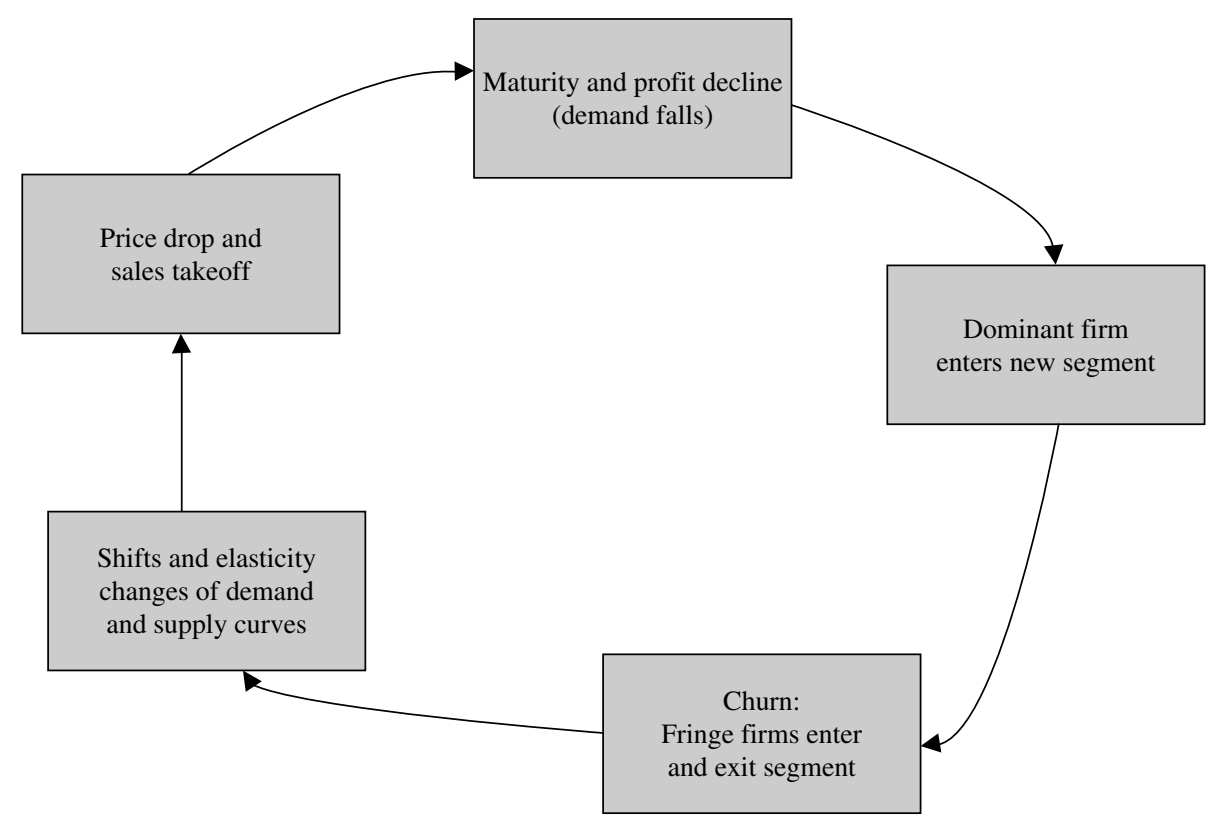

Note. Neighboring stages may happen contemporaneously.

Stackelberg leader (Gaskins 1971, Caves et al. 1984). These characteristics imply that a dominant firm should be characterized by substantial market share. Empirical studies of dominant firms have identified dominance primarily by a firm's market share, with a share of $40 \%$ or $50 \%$ used as the typical threshold for dominance (Yamawaki 1985, White 1981). We follow this convention, assuming in our theory that a dominant firm behaves as a low-cost Stackelberg leader and empirically identifying HP as the sole dominant firm in the laser printer industry based on a market share threshold of $40 \%$.

With this definition, Figure 1 outlines the basic dynamic theoretical framework developed to explain the timing and direction of dominant firm entry and the response of fringe firms in a multisegment market, and in particular, in the desktop laser printer industry. The next four subsections explore this framework in detail, but the basic outline is as follows: The dominant firm focuses on competing within its existing segment until it encounters reduced (expected) profitability in that segment, due to declining price or declining sales growth or both. This triggers the firm's entry into a new segment where it can better utilize its resources and investment. The selection of the new segment balances the tension between two basic forces: the firm's desire to exploit its innovative capabilities and its desire to avoid cannibalization of its current product portfolio. This causes a dominant firm to seek segments in which it can exploit its existing technological capabilities, but to skip neighboring segments to avoid cannibalization. When the dominant firm enters a new segment, it acts as a low-cost
Stackelberg price leader, setting prices that are below those of the fringe firms already in the segment. This sparks a sales takeoff.

Fringe firms, in turn, respond to the entry of the dominant firm. A set of fringe firms whose resources and capabilities are well suited for competing in the shadow of the dominant firm enter the segment on the heels of the dominant firm. However, incumbent fringe firms tend to exit the segment, presumably because their resources and capabilities, although appropriate for the pre-dominant firm period, are not well suited for the selection environment in the postdominant firm era. This entry and exit behavior by these different types of firms results in a churn in the segment. Many of the exiting fringe firms continue to compete in other segments of the industry, often entering new segments as they exit the existing one. Ultimately, this segment experiences sales growth decline, and the cycle begins again.

\subsection{Moving the Giant: What Motivates the Firms to Move?}

There are many motivating factors that may cause a dominant firm to seek new segments. We focus on three: (1) the profitability of the current segment, (2) the profitability of the potential segment, and (3) the costs the firm faces in moving from one segment to another (costs of growth). Assume that the dominant firm exists in a market segment, Segment 1. If the firm can expand costlessly, then the profitability of Segment 1 should have no effect on the firm's decision to enter Segment 2; rather, the firm moves into Segment 2 if the new segment is sufficiently 
attractive. For a firm that faces adjustment costs for expansion, notably an increasing marginal cost of growth in a given segment as well as a fixed cost of expanding into new segments (e.g., Klepper 1996, 2002), the calculus is different. In this case, expanding into Segment 2 occurs only if it is more attractive than growing in Segment 1; thus, the profitability of both segments drives the entry decision. The firm will enter Segment 2 only if the discounted expected profits from Segment 2 minus the expansion and growth costs are greater than the discounted expected profits from Segment 1 minus the growth costs. ${ }^{2}$ Assuming that the dominant firm's costs do not change over time within a segment, it is straightforward to see that as quantity or price drops in Segment 1, ceteris paribus, the hurdle for entering Segment 2 declines. That is, demand slowdown in one segment creates opportunities to grow in new segments (e.g., freeing factory capacity that can be used to grow into Segment 2).

Hypothesis 1 (H1). When there are growth costs, a market price or sales drop in a dominant firm's existing segment(s), ceteris paribus, makes it more likely to enter a new segment.

\subsection{The Dominant Firm's Entry Decision: Which Segment?}

How does a dominant firm choose which new segment to enter? Theoretical and empirical evidence on diversification indicates that a firm will enter new industries in which it can exploit its existing technological capabilities (Silverman 1999, Helfat and Lieberman 2002). In a formal treatment of this question, Klepper (2002) develops a model that describes industry evolution in terms of entry, innovation, growth, and exit of both new firms and diversifying firms in an industry. Much of Klepper's model turns on the differential research productivity of large firms, whereby those firms whose research efforts are more productive in an industry ultimately are more successful and are therefore more likely to enter in the first place. In a study of the television manufacturing industry, Klepper and Simons (2000) find support for this: producers of home radios (whose R\&D expertise was directly useful in TV production) were among the earliest and most successful entrants to this industry; the larger and more experienced were these firms in home radios, the more likely their entry and success in television production.

To the extent that distinct product segments within an industry are conceptually similar to distinct industries, a similar pattern in segment entry will exist.

${ }^{2}$ This could be stated mathematically as $E\left[\int_{t_{0}}^{\infty}\left(p_{2}-c_{2}\right) q_{2} \cdot d t\right]>$ $E\left[\int_{t_{0}}^{\infty}\left(p_{1}-c_{1}\right) q_{1} \cdot d t\right]-m$, where $p_{i}, c_{i}, q_{i}$ are the price, cost, and quantity of segment $i, m$ is the cost of expansion, and $t_{0}$ is the time of entry into class $i$.
Indeed, in a study of entry by incumbents into new "subfields" within the medical device industry, Mitchell (1989) found that these firms readily entered those subfields in which their firm-specific assetsincluding technological resources-provide value, and less readily entered subfields that would benefit less from their firm-specific assets.

Hypothesis 2 (H2). A firm will be more likely to enter a segment in which it can exploit its existing technological capabilities relative to segments in which it cannot exploit these capabilities.

The above hypothesis suggests that firms will enter segments where they can exploit economies of scope in the direction of their research capability. This is frequently taken to mean that a firm will choose to enter "nearby" or "proximate" segments because a firm's research capability (and other assets) is likely to decrease in value as distance in product space increases (e.g., Wernerfelt and Montgomery 1988). However, there is a tension between the productiondriven prediction above and concerns raised when considering the demand and competitive implications of segment entry. As a large literature on product line decisions (e.g., Moorthy 1984) and multiproduct entry (e.g., Brander and Eaton 1984) demonstrates, a firm that introduces products that are too proximate risks cannibalizing its own higher-margin products. This is exacerbated in the face of actual or potential competition: when a firm competes in multiple product segments in close proximity to each other such that they are partial substitutes, the firm has particularly weak incentives to behave aggressively with respect to any one of the product segments because increased competition in that segment will not only reduce profits in that segment but will draw demand from the profitable proximate segment (Katz 1984, Judd 1985, Desai 2001). Recognizing this, potential and actual rivals can take advantage of the multiproduct firm's muted incentives. Consequently, while a dominant firm has a supply-side incentive to enter segments that are proximate, the firm also has a demand-side incentive to enter segments that are more distant, hence, less directly substitutable. This implies that even as it enters new segments to exploit its research strength, the firm will have an incentive to avoid immediately adjacent segments. If this incentive is strong enough, then the firm will "skip" segments to avoid cannibalization of existing products and to remain credibly aggressive in each segment.

In contrast, to the extent that fringe firms are pricetakers in their markets, a fringe firm will be less concerned about a commitment to aggressive competitive behavior. We therefore expect fringe firms to be attracted to adjacent segments to best exploit their existing capabilities. 
Hүротнеsis 3A (H3A). A fringe firm will be more likely to enter a segment adjacent to its existing segment(s) relative to segments further away.

Нypothesis 3B (H3B). A dominant firm will be less likely to enter a segment adjacent to its existing segment(s) relative to segments further away.

\subsection{Prices and Demand}

Previous studies on industry evolution have noted a substantial price decline and sales takeoff contemporaneous with, or subsequent to, the entry of new firms. These studies have attributed this price and quantity change to an outward shift in the supply curve caused by new, low-cost entrants (Goldner and Tellis 1997, Bass 1980), and an outward shift in the demand curve caused by product improvements, expanded distribution, and increased consumer awareness (Agarwal and Bayus 2002). There is a third (not mutually exclusive) possibility: the demand curve can become more elastic over time. These three cases are briefly discussed below, and the electronic appendix develops them in greater detail (provided in the e-companion). ${ }^{3}$

Our theory takes these ideas and further explains a causal mechanism of the sales takeoff by introducing two new elements: a dominant firm and a segmented industry. To date, there is very little theory integrating industry evolution, dominant firms, and segmented markets creating, what we believe, is an opportunity to explore the dynamics of supply and demand in these cases. As such, our model opens the door to further theoretical and empirical analysis of segment evolution.

In our model, the dominant firm could cause all three of the demand and supply effects noted above. With respect to shifting the supply curve, the dominant firm maintains a marginal cost advantage derived from its ability to achieve higher economies of scale and its investment in cost-reducing $R \& D$ (Klepper 1996). The profit-maximizing price for a Stackelberg dominant firm is thus lower than the profit-maximizing price of a higher-cost fringe firm (Saloner et al. 2001). Entry of the dominant firm into a segment will lead to a fall in equilibrium prices and, consequently, a sales takeoff.

With respect to shifting the demand curve, the dominant firm can increase product awareness through branding and advertising (Agarwal and Bayus 2002). Anderson and Tushman (1990) study the establishment of a dominant design in several industries and find that industry sales rise dramatically after a dominant design is established. Although this is

\footnotetext{
${ }^{3}$ An electronic companion to this paper is available as part of the online version that can be found at http://mansci.journal.informs. org/.
}

distinct from the entry of a dominant firm, Anderson and Tushman note that the presence of a "dominant producer" can serve to convince customers that uncertainty about the industry's products has been resolved, and thus encourage them to increase their purchasing. This will also cause a sales takeoff because the demand shift will independently lead to more potential buyers entering the market. Note, however, that in the absence of an accompanying supply shift or in the presence of small or moderate supply shift, the demand shift will actually cause prices to rise as unit sales increase-contrary to the findings in most empirical work in the area.

Third, and related to the demand shift, a dominant firm's entry can also change the elasticity, or shape, of the demand curve in a segment by changing some buyers' willingness to pay (WTP) more than others. Previous scholars have largely overlooked this possibility. This is different from shifting demand, as the change in elasticity has a distinct effect on optimal price. The demand curve will become more elastic if low-WTP consumers increase their WTP (differentially more than high-WTP buyers) because of advertising, brand awareness, or more legitimacy conferred to the segment (Haveman 1993). It is likely that smaller firms will have difficulty replicating this effect, given that new, small firms in new industries suffer from a legitimacy problem that slows sales (Aldrich and Fiol 1994).

Given that the increased WTP associated with dominant firm entry will likely affect those at the bottom of the demand curve, below the current equilibrium price, the increasing elasticity of demand by itself will have no effect on equilibrium sales or price. However, combined with a supply shift, an increase in demand elasticity will magnify the sales increase, while attenuating the price decline somewhat.

Thus, with a sufficiently large shift in demand, a sales takeoff can be associated with either a decline or increase in segment price. However, to the extent that the combination of supply shift and change in elasticity of demand exceed a demand shift, a sales takeoff will be associated with a decline in price. For the reasons described above, we expect the entry of a dominant firm into a segment to have a significant impact on both supply and the elasticity of demand. Thus, we predict:

Hypothesis 4 (H4). After a dominant firm enters a segment, the price decline in that segment will accelerate.

Hypothesis 5 (H5). After a dominant firm enters a segment, sales in that segment will increase.

One concern might arise regarding these hypotheses. If the dominant firm is unusually good at forecasting future demand, then the sales takeoff could 
be a result of demand forecasting rather than demand creation, as posited by the theory. While we cannot definitively rule out the possibility of demand forecasting, we can point to a number of pieces of evidence that suggest this is not the case. We examine this logic in $\S 4$ and the electronic appendix.

\subsection{The Effect of the Dominant Firm's Entry on Fringe Firms}

The final piece of the dynamic process is an analysis of what happens to fringe firms' entry and exit behavior when a dominant firm enters the segment. Current theoretical thinking on this topic yields ambiguous results. On one hand, the neoclassical model argues that dominant firms will drive out fringe firms because the dominant firm will be able to exploit economies of scale in its operations. Moreover, as a dominant firm increases competitive pressure within a segment due to enhanced research productivity and its incentive to invest heavily in $R \& D$, such entry should encourage fringe firm exit and discourage subsequent fringe firm entry (Klepper 1996). On the other hand, models of dominant firm behavior sometimes derive conditions in which the dominant firm will set a price umbrella that allows fringe firms in the market to prosper (Gaskins 1971), attenuating competitive pressure. Further, if entry by a dominant firm provides a positive signal about future demand in a given segment, then this should cause fringe firms to follow a dominant firm in the expectation that doing so will lead them to attractive segments (Haveman 1993). Thus, the dominant firm's entry might attract fringe firm entry and discourage exit.

We propose that the entry of the dominant firm causes both of these effects, leading to churn in the segment. There are two basic types of fringe firms: those whose capabilities and resources are well suited to profiting in a segment with a dominant firm, and those whose capabilities and resources are not well suited to this situation. When the dominant firm enters the segment, the competitive landscape changes. As often happens when a discrete event such as an innovation or regulatory change occurs, firms that were in the segment prior to the event are likely to exit because they are poorly equipped to face the new market conditions (Henderson and Clark 1990, Nickerson and Silverman 2003). Another set of firms will enter after the event to take advantage of the new conditions (Anderson and Tushman 1990). These firms are more likely to survive post-dominant firm entry because they are equipped to compete in such conditions. In this sense, fringe firms are not homogeneous as the literature has suggested (e.g., Hannan and Freeman 1989), but rather are heterogeneous in their resources and capabilities. Dominant firm entry causes the combination of these two events-the exit of incumbent fringe firms and entry of new fringe firms-resulting in substantial churn in the segment. ${ }^{4}$

Hypothesis 6 (H6). Dominant firm entry in a segment will be accompanied by a wave of fringe firm entry in that segment.

Hүротнеsis 7 (H7). Ceteris paribus, fringe firms that are in a segment before the dominant firm enters are more likely to exit the segment than firms that enter after the dominant firm enters.

The dynamic cycle of the interaction between the dominant and fringe firms then repeats itself as demand growth in the focal segment declines. Having developed a framework for thinking about the dynamics of dominant and fringe firm behavior in the context of a multisegment industry's evolution, we turn to an empirical evaluation of the framework using data from the desktop laser printer industry.

\section{The Laser Printer Industry}

As the personal computer market expanded in the 1980s, so too did the market for desktop printers in the United States. HP introduced the first desktop laser printer for the retail market in 1984. By the end of 1985, 17 firms had introduced 23 models of printers. At its peak in 1990, the industry had more than 100 firms, but by 1996 the number of firms had fallen to 87. HP maintained at least $45 \%$ U.S. market share each year between 1984 and 1996. Three other firms (Apple, Fujitsu, and IBM/Lexmark) held between $10 \%$ and $20 \%$ market share for at least one year. No other firm held more than $9 \%$ market share during any year. Thus, HP is the sole dominant firm in this industry, and all other firms are fringe firms. ${ }^{5}$

A desktop laser printer is made, essentially, of three main components-laser engine, controller card (the electronics), and exterior features such as toner cartridge, feeder tray, and plastic outside box. To create a printed page, the paper passes from the feeder tray to the laser engine, where the page is electrically charged. Fine-grain toner of the opposite charge is attracted to the paper, heated, and fused to the page

\footnotetext{
${ }^{4}$ It is beyond the scope of this paper to identify the distinct characteristics of firms that precede versus follow the dominant firm into a market. However, some possibilities are that followers have low-cost positions, high-quality products, or marketing structures designed to benefit from the positive externalities of the dominant firm's advertising expenditure. We return to this in $\$ \S 4$ and 5 .

${ }^{5}$ Our empirical results hold if we expand the definition of dominant firm to include Apple, Fujitsu, and IBM/Lexmark. Note that "fringe firm" indicates that a firm held a small market share in this industry. It does not necessarily mean that the firm itself is small. For example, Ricoh, Xerox, and Okidata are defined as fringe firms in this industry, although they are large companies based on their other businesses.
} 
Figure 2 Product Distribution and Classes

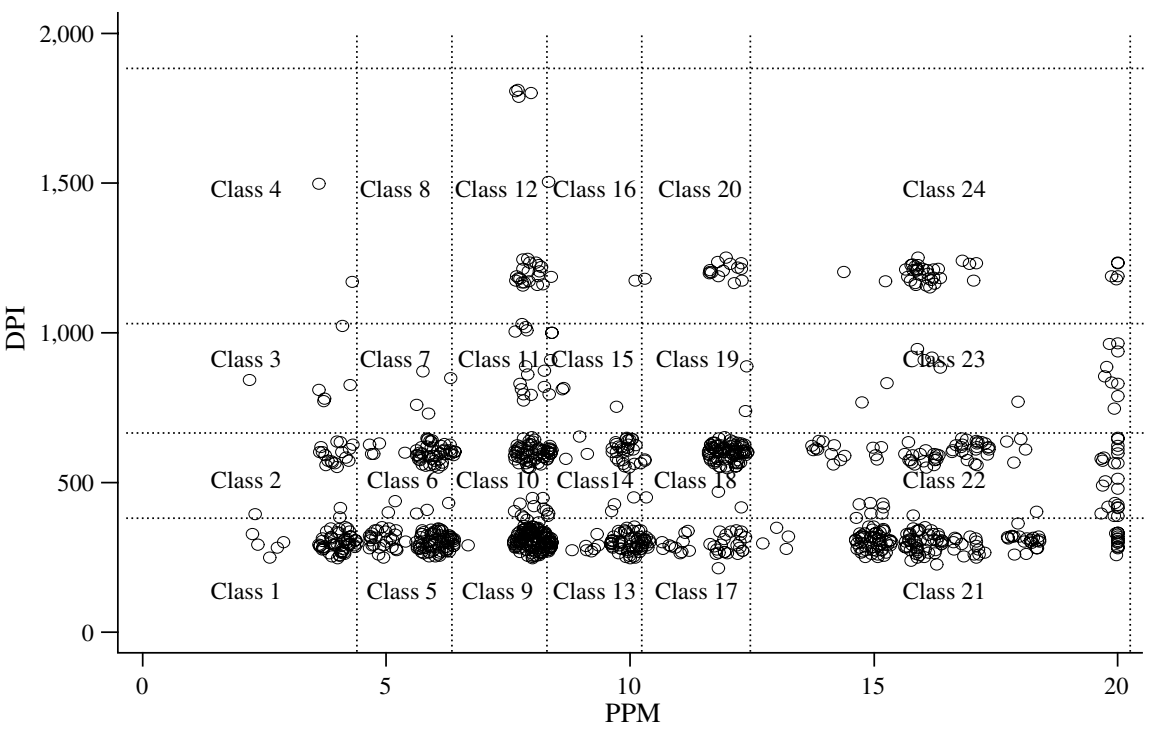

Note. Each small circle represents a printer.

by the fuser assembly of the laser engine. The paper is then ejected to the exterior paper tray. The controller card governs the process and provides the many features that a given laser printer offers.

The vast majority of laser printer producers purchase laser engines on the open market, choosing among 20 suppliers. ${ }^{6}$ Canon is the dominant supplier, with $60 \%$ market share and $90 \%$ share of $\mathrm{HP}^{\prime} \mathrm{s}$ purchases during the sample period. In contrast, the majority of laser printer producers make their own controller cards. Finally, virtually all laser printer makers purchase exterior features on the open market.

Two features of the laser printer industry are particularly salient to this study. First, the key characteristics of a laser printer are speed, measured in pages per minute (PPM), and resolution, measured in dots per inch (DPI). These are the two characteristics most prominently assessed in popular press rankings of printers (e.g., Consumer Reports 2005). Additionally, in a hedonic analysis of laser printers, de Figueiredo and Kyle $(2005,2006)$ find that speed and resolution are two of the most important characteristics (with memory being a third important characteristic). Figure 2 provides the location in PPM-DPI space of each laser printer model introduced between 1984 and 1996. Each circle represents a printer model. A striking feature of this scatterplot is that printers are clustered tightly into distinct groups in this space. To identify the product classes, or segments, in this industry

\footnotetext{
${ }^{6}$ Exceptions include Fujitsu and Ricoh, which are vertically integrated into printers and engines. Even these firms typically offer their engines for sale on the open market within a few months of introducing their own printers with such engines, thus enjoying only a very short period of internal-only use.
}

we pursued three avenues. First, we used the clustering in Figure 2 and accompanying statistical tests to identify segments where printers of roughly the same DPI and PPM are located together (see de Figueiredo and Kyle 2006 for more details). Second, we consulted trade journals and research reports to determine how experts segmented the industry. Finally, we met with firm managers to determine how they and their customers thought about segments and competition. From this we developed the 24 product classes in Figure 2.

Through 1996, there was little change in this classification scheme. Beginning in 1997, with technological advances in color printers, multifunction printers, and network printers, the segment definitions began to become more blurred. Hence, our data purposefully stop in 1996. These are the segments that we use to examine entry and exit patterns in these data. We have experimented with small changes to the segment definitions, and they do not change the qualitative results presented in this paper.

Second, the locus of innovation differs between these two characteristics. Speed is largely determined by innovations in the laser engine. The speed with which a printer operates is a mechanical process that is constrained by the maximum speed of the laser engine. Although a laser printer producer can slow down the speed of an engine through the code on the controller card, it is difficult for a printer to print faster than its designated engine speed. Thus, innovation in the PPM dimension is driven largely by engine manufacturers. In contrast, although resolution depends in part on the engine, it is also determined substantially by the controller card. Notably, software techniques can raise the resolution of a 
Figure 3 Entry into Laser Printer Product Classes

\begin{tabular}{|c|c|c|c|c|c|}
\hline $\begin{array}{c}\text { Class } 4 \\
\text { 1st entrant: } 1993\end{array}$ & $\begin{array}{c}\text { Class } 8 \\
\text { 1st entrant: NA }\end{array}$ & $\begin{array}{c}\text { Class } 12 \\
\text { 1st entrant: } 1990\end{array}$ & $\begin{array}{c}\text { Class } 16 \\
\text { 1st entrant: } 1995\end{array}$ & $\begin{array}{c}\text { Class } 20 \\
\text { 1st entrant: } 1991\end{array}$ & $\begin{array}{c}\text { Class } 24 \\
\text { 1st entrant: } 1994 \\
\text { HP enters: } 1996\end{array}$ \\
\hline $\begin{array}{c}\text { Class } 3 \\
\text { 1st entrant: } 1991\end{array}$ & $\begin{array}{c}\text { Class } 7 \\
\text { 1st entrant: } 1995\end{array}$ & $\begin{array}{c}\text { Class 11 } \\
\text { 1st entrant: } 1988\end{array}$ & $\begin{array}{c}\text { Class } 15 \\
\text { 1st entrant: } 1996\end{array}$ & $\begin{array}{c}\text { Class } 19 \\
\text { 1st entrant: } 1992\end{array}$ & $\begin{array}{c}\text { Class } 23 \\
\text { 1st entrant: } 1991\end{array}$ \\
\hline $\begin{array}{c}\text { Class } 2 \\
\text { 1st entrant: } 1990 \\
\text { HP enters: } 1993\end{array}$ & $\begin{array}{c}\text { Class } 6 \\
\text { 1st entrant: } 1987 \\
\text { HP enters: } 1995\end{array}$ & $\begin{array}{c}\text { Class } 10 \\
\text { 1st entrant: } 1990 \\
\text { HP enters: } 1992\end{array}$ & \begin{tabular}{|c} 
Class 14 \\
1st entrant: 1988
\end{tabular} & $\begin{array}{c}\text { Class } 18 \\
\text { 1st entrant: } 1989 \\
\text { HP enters: } 1992\end{array}$ & $\begin{array}{c}\text { Class 22 } \\
\text { 1st entrant: } 1987 \\
\text { HP enters: } 1993\end{array}$ \\
\hline $\begin{array}{c}\text { Class 1 } \\
\text { 1st entrant: } 1989 \\
\text { HP enters: } 1989\end{array}$ & $\begin{array}{c}\text { Class } 5 \\
\text { 1st entrant: } 1987\end{array}$ & $\begin{array}{c}\text { Class 9 } \\
\text { 1st entrant: } 1984 \\
\text { HP enters: } 1984\end{array}$ & $\begin{array}{c}\text { Class 13 } \\
\text { 1st entrant: } 1986\end{array}$ & $\begin{array}{c}\text { Class } 17 \\
\text { 1st entrant: } 1986\end{array}$ & $\begin{array}{c}\text { Class } 21 \\
\text { 1st entrant: } 1986 \\
\text { HP enters: } 1989\end{array}$ \\
\hline
\end{tabular}

printer through various mechanisms (e.g., offsetting the electrical charges by a half a step). Thus, innovation in resolution can be driven by the printer producer's research capability in achieving particular DPI ranges.

This has implications for the empirical testing of the hypotheses derived above. Because innovation by laser printer firms is centered around the software that supports particular levels of printer resolution, while innovation along the speed dimension is generally undertaken by laser engine suppliers and hence purchased through the market for engines, the firmspecific research capabilities of laser printer firms are thus likely to be specialized to particular DPIs. These capabilities can be combined with different engines to serve segments with different PPM requirements. To the extent that a laser printer firm seeks to enter classes where it can exploit its existing technological capabilities, such a firm is likely to enter new PPM classes within its existing DPI range. In contrast, entering new DPI classes within an existing PPM range offers fewer opportunities for a printer firm to exploit its firm-specific research capability.

Figure 3 shows the pattern of class entry by HP and pioneering fringe firms. Three features stand out. First, in seven of these classes fringe firm entry precedes HP entry, which allows for comparison of competitive processes before and after $\mathrm{HP}^{\prime}$ s entry. Second, the initial dates of entry indicate that, over time, firms have pioneered increasingly high-resolution classes. In contrast, firms generally began in the center of PPM space and have moved into both higherand lower-speed classes, suggesting a "dual frontier" of innovation (de Figueiredo and Kyle 2006). The variation in pioneering dates of classes raises the possibility that exogenous factors, such as technological constraints, may have made some classes infeasible for entry in early years of the industry. In our statistical analyses below, we deal with this by considering a class to be "at risk" of entry only once it has been entered by at least one firm. ${ }^{7}$

Third, HP ultimately enters nine of the 24 segments. HP's entry is particularly prevalent in the lowerresolution segments. HP also appears to "skip" segments in PPM space. For example, HP competes in Classes 1, 9, and 21, but chooses not to enter Class 5 (which is adjacent to 1 and 9 in PPM space) or 13 or 17 (which are adjacent to 9 and 21, respectively). Thus, rather than extending its product line to the most proximate segment, where one might expect its existing advantages to be most leverageable, HP chooses to locate further away. ${ }^{8}$ We explore this statistically below.

\section{Empirical Analysis}

We compiled life histories of each product and firm in the desktop laser printer industry, from its inception in

\footnotetext{
${ }^{7}$ Another concern could be that Canon, as the dominant supplier to this industry, might influence segment entry and sales patterns. Notably, if Canon were to sell printers only (or first) to HP, and Canon engines drive customer demand, then the association between HP's entry and the sales takeoff could be spurious. To assuage this concern, we note that Canon engines appear in at least one model in every populated segment of the industry. Also, in every segment that HP enters, at least one firm that preceded HP into the segment used Canon engines before HP's entry.

${ }^{8}$ Ultimately, however, HP faces a trade-off between staying in its existing resolution range and avoiding adjacent segments. At this point (1992-1993), HP begins to locate in neighboring segments rather than move to a new resolution range, although $\mathrm{HP}^{\prime}$ s final entry in 1996 is to a nonadjacent segment in a new resolution range.
} 
1984 to 1996. Our primary data source was Dataquest's annual SpecCheck report on page printers, which is the single most comprehensive public database on these printers. SpecCheck provides information on a variety of printer characteristics including manufacturer, initial ship date, speed in PPM, resolution in DPI, and other features. To fill in missing data from early years in the industry, we supplemented this data source with information from PC Magazine and PC World. In addition, we obtained price and quantity data from a separate, nonpublic Dataquest market research database and from a private consulting firm that had engaged in a long-term study of this industry. We believe that the resulting data set is the most comprehensive available. Over the 13-year period, we recorded 3,836 printer-year observations that aggregate up to 1,882 firm-class-year observations.

To test our hypotheses, we analyze entry into and exit from product classes, both at the firm and the class level. We also analyze the effect of dominant firm entry on price and sales unit volume. Consequently, we construct five distinct dependent variables to support these analyses.

1. Entry $y_{i j t}$ is a categorical variable set equal to one if firm $i$ enters class $j$ in year $t$, and zero otherwise. Firm $i$ enters class $j$ when it introduces its first product into that class. Subsequent introductions by firm $i$ of additional products into that class are not considered entries.

2. EntryCount ${ }_{j t}$ is a count of the number of firms that enter class $j$ in year $t$.

3. Price $_{k i j t}$ is measured as the price charged for printer $k$ produced by firm $i$ in class $j$ in year $t$. We report models using the list price because the list price data are significantly more complete than the street price data. Results using the street price data are substantively the same.

4. UnitSales ${ }_{j t}$ is measured as the natural log of the number of printer units sold (plus 1) in class $j$ in year $t$. Unit sales data, by printer model, is aggregated at the class-year level.

5. Exit ${ }_{i j t}$ is a categorical variable set equal to one if firm $i$ exits class $j$ in year $t$, and zero otherwise. Firm $i$ exits class $j$ when it ceases to ship any product in that class. If firm $i$ withdraws one or more products from class $j$, but continues to sell at least one other product in that class, it does not exit the class.

We employ a variety of independent variables that measure the sales growth in classes, the degree of competition in the focal class, the number of classes in which the focal firm participates, timing of entry of the focal firm, timing of HP's entry (interacted with other variables), and several clocks that measure elapsed time from a relevant event. These variables are defined in Table 1. Descriptive statistics can be found in Table EC.1 of the electronic appendix.
The mean Price charged for a printer between 1984 and 1996 is $\$ 4,240$. The mean UnitSales for a class during this time period is roughly 117,000 units per year. However, unit sales vary tremendously from zero in some class years to more than 1,000,000 in others.

To test our firm-level hypotheses about entry and exit, we estimate piecewise hazard rate models of the probability of a firm entering or exiting a given class. ${ }^{9}$ To test our class-level hypotheses about entry, where the dependent variable is a count, we estimate negative binomial models. Finally, to test our hypotheses about price and sales, where the dependent variables are continuous, we estimate ordinary least squares (OLS) models with class random effects. The results presented here are largely robust if we expand our definition of dominant firm to include firms that have $10 \%$ market share in a given year.

\subsection{Results}

4.1.1. Entry. Table 2 presents results of our tests of Hypotheses 1-3, concerning the timing and direction of entry into new classes by dominant and fringe firms in the laser printer industry. To examine whether Hypothesis 1 is valid, we examine how a change in quantity sold in a dominant firm's existing segment affects the probability the firm will enter a new segment. To test Hypothesis 2, we explore whether firms that enter new segments pursue segments in the same DPI range as their existing segments, thus exploiting their current DPI capabilities. Finally, to test Hypotheses $3 \mathrm{~A}$ and $3 \mathrm{~B}$, we examine whether dominant and fringe firms skip neighboring segments when they choose new segments to enter. To gain initial traction on these hypotheses, we look at the descriptive data. Figure 4 provides descriptive evidence on what motivates the dominant firm to enter new markets. The flattening or decline of sales in classes where HP participates seems to precipitate new entry by HP. Combining this with Figure 3, there appears to be three patterns in the data: (a) HP enters a new segment when it experiences a slowdown in sales growth in existing segments; (b) HP extends its product line along the DPI dimension; and (c) HP seems to avoid adjacent segments until it can no longer do so while staying in the same DPI range. These patterns are consistent with Hypotheses 1, 2, $3 \mathrm{~A}$, and 3B. Although the figures are useful evidence for the theory, Table 2 presents a hazard rate estimation to more rigorously test these hypotheses.

Model 1 provides a baseline piecewise exponential hazard rate model with robust standard errors clustered on the firm. ${ }^{10}$ Model 2 introduces the indepen-

\footnotetext{
${ }^{9}$ We thank Glenn Carroll for advising us on this approach. The full analysis and convergence to the pieces is available from the authors. The results are robust to alternate hazard-rate specifications.

${ }^{10}$ We present the exponentiated coefficients from the hazard-rate estimation rather than the hazard ratio for clarity.
} 
Table 1

Definition of Independent Variables and Summary of Predictions

\begin{tabular}{|c|c|c|}
\hline Variable & Definition & Prediction \\
\hline \multicolumn{3}{|l|}{ Industry-level variables } \\
\hline IndustryClock & Age of industry at time $t$, set equal to $t-1984$ & \\
\hline IndustryDensity ${ }_{t}$ & Number of firms in industry at time $t$ & \\
\hline IndustryDensityS $q_{t}$ & IndustryDensity squared $^{2}$ & \\
\hline NumSegmentsOpened ${ }_{t}$ & Number of segments that have had at least one entry at time $t$ & \\
\hline \multicolumn{3}{|l|}{ Class-level variables } \\
\hline ClassClock $_{j t}$ & $\begin{array}{l}\text { Age of class } j \text { at time } t \text {, set equal to } t \text {-year that class had } \\
\text { first entrant }\end{array}$ & \\
\hline ClassDensity $_{j t}$ & Number of firms in class $j$ at time $t$ & \\
\hline ClassDensity $S q_{j t}$ & ClassDensity $_{j t}$ squared & \\
\hline SalesGrowth $_{j t}$ & $\begin{array}{l}\text { Unit sales in class } j \text { at time } t \text { minus unit sales in class } j \text { at } \\
\text { time }(t-1) \text {, divided by unit sales in class } j \text { at time }(t-1)\end{array}$ & \\
\hline HPInClass & One if HP competes in class $j$ in year $t$, and zero otherwise & $\begin{array}{l}\text { H4: Negative in price model } \\
\text { H5: Positive in sales model } \\
\text { H6: Positive in entry count model }\end{array}$ \\
\hline HPClock $_{j t}$ & $\begin{array}{l}\text { HP's tenure in class } j \text { at time } t \text {, set equal to } t-\text { year that HP } \\
\text { entered class } j\end{array}$ & \\
\hline \multicolumn{3}{|l|}{ Firm-level variables } \\
\hline FirmAge $_{i t}$ & $\begin{array}{l}\text { Age of firm at time } t \text {, set equal to } t-\text { year that firm } i \text { first } \\
\text { entered industry }\end{array}$ & \\
\hline FirmAgeS $q_{i t}$ & FirmAge $_{i t}$ squared & \\
\hline SalesGrowthInCurrentClasses $_{i t}$ & $\begin{array}{l}\text { Sum of unit sales across all classes in which firm } i \\
\text { competes at time } t \text { minus sum of unit sales across same } \\
\text { classes at time }(t-1) \text {, divided by sum of unit sales across } \\
\text { same classes at time }(t-1)\end{array}$ & \\
\hline NumClasses $_{i t}$ & Number of classes that firm $i$ competes in at time $t$ & \\
\hline HPDum $_{i}$ & One if firm $i$ is $\mathrm{HP}$, and zero otherwise & \\
\hline \multicolumn{3}{|l|}{ Firm-class-level variables } \\
\hline SameDPI $_{i j t}$ & $\begin{array}{l}\text { Number of classes that firm } i \text { already competes in at time } t \\
\text { that are in the same DPI row as class } j \text {, normalized }\end{array}$ & $\mathrm{H} 2$ : Positive in entry model \\
\hline SamePPM $M_{i j t}$ & $\begin{array}{l}\text { Number of classes that firm } i \text { already competes in at time } t \\
\text { that are in the same PPM column as class } j, \text { normalized }\end{array}$ & \\
\hline Neighbor $_{i j t}$ & $\begin{array}{l}\text { One if, at time } t \text {, firm } i \text { already competes in at least one class } \\
\text { that is directly adjacent to class } j \text {, zero otherwise }\end{array}$ & H3A: Positive in entry model \\
\hline HPPreceder $_{i j}$ & $\begin{array}{l}\text { One if firm } i \text { entered class } j \text { before HP has entered class } j \\
\text { (NB: if HP has not entered class } j \text { by 1996, then this is one } \\
\text { for all firms in class } j \text {, zero otherwise) }\end{array}$ & \\
\hline HPPrecederBeforeHPEntry $_{i j t}$ & $\begin{array}{l}\text { One if firm } i \text { entered class } j \text { before HP has entered class } j \\
\text { and HP has not yet entered class } j \text { as of time } t \text {, zero otherwise }\end{array}$ & \\
\hline HPPrecederAfterHPEntry ${ }_{i j t}$ & $\begin{array}{l}\text { One if firm } i \text { entered class } j \text { before HP has entered class } j \\
\text { and HP has entered class } j \text { as of time } t \text {, zero otherwise }\end{array}$ & H7: Positive in exit model \\
\hline \multicolumn{3}{|l|}{ HP interaction variables } \\
\hline$H P *$ SalesGrowth ${ }_{i j t}$ & Interaction term between HPDum and SalesGrowth & \\
\hline$H P *$ SalesGrowthlnCurrentClasses ${ }_{i t}$ & $\begin{array}{l}\text { Interaction term between HPDum and } \\
\text { SalesGrowthInCurrentClasses }\end{array}$ & H1: Negative in entry model \\
\hline$H P * S a m e D P l_{i j t}$ & Interaction term between HPDum and SameDPI & \\
\hline$H P * S_{\text {SamePPM }}$ & Interaction term between HPDum and SamePPM & \\
\hline$H P *$ Neighbor $_{i j t}$ & Interaction term between HPDum and Neighbor & H3B: Negative in entry model \\
\hline
\end{tabular}

dent variable SalesGrowthInCurrentClasses. Models 35 introduce additional firm variables and HP-related variables. Because a likelihood-ratio test indicates that the explanatory power of Model 5 is greater than that of preceding models, and because the magnitudes of the coefficients across these models are relatively stable, we direct our attention to Model 5.

The focal variables to test Hypothesis 1 are the direct and interactive effects of SalesGrowthInCurrent-
Classes and HP*SalesGrowthInCurrentClasses. The coefficient on the main effect is negative but not statistically significant. This suggests that fringe firms are not motivated to enter new classes when sales growth in their existing classes declines. However, the coefficient on the interaction term, HP * SalesGrowthInCurrentClasses, is large (in absolute value), statistically significant, and negative. This result is consistent with Hypothesis 1; after controlling for a range of firm, 
Table 2 The Timing and Direction of Entry into a New Segment

\begin{tabular}{|c|c|c|c|c|c|}
\hline \multirow[b]{2}{*}{ Variable } & \multicolumn{5}{|c|}{ Model } \\
\hline & (1) & (2) & (3) & (4) & (5) \\
\hline Time piece 1 & $\begin{array}{c}-18.815^{* * *} \\
(0.454)\end{array}$ & $\begin{array}{c}-19.444^{* * *} \\
(0.456)\end{array}$ & $\begin{array}{c}-18.161^{* * *} \\
(0.484)\end{array}$ & $\begin{array}{c}-18.490^{* * *} \\
(0.453)\end{array}$ & $\begin{array}{c}-17.812^{* * *} \\
(0.440)\end{array}$ \\
\hline Time piece 2 & $\begin{array}{c}-5.558^{* * *} \\
(1.266)\end{array}$ & $\begin{array}{c}-5.482^{* * *} \\
(1.270)\end{array}$ & $\begin{array}{c}-4.999^{* * *} \\
(1.323)\end{array}$ & $\begin{array}{c}-5.348^{* * *} \\
(1.312)\end{array}$ & $\begin{array}{c}-5.560^{* * *} \\
(1.261)\end{array}$ \\
\hline Time piece 3 & $\begin{array}{c}-2.964^{* * *} \\
(0.481)\end{array}$ & $\begin{array}{c}-2.920^{* * * *} \\
(0.482)\end{array}$ & $\begin{array}{c}-2.736^{* * * *} \\
(0.485)\end{array}$ & $\begin{array}{c}-3.088^{* * * *} \\
(0.465)\end{array}$ & $\begin{array}{c}-3.293^{* * *} \\
(0.465)\end{array}$ \\
\hline Time piece 4 & $\begin{array}{c}-2.279 * * * \\
(0.525)\end{array}$ & $\begin{array}{c}-2.221^{* * * *} \\
(0.528)\end{array}$ & $\begin{array}{c}-2.220^{* * * *} \\
(0.559)\end{array}$ & $\begin{array}{c}-2.529^{* * * *} \\
(0.533)\end{array}$ & $\begin{array}{c}-2.764^{* * *} \\
(0.533)\end{array}$ \\
\hline Time piece 5 & $\begin{array}{c}-0.840 \\
(0.676)\end{array}$ & $\begin{array}{c}-0.847 \\
(0.682)\end{array}$ & $\begin{array}{r}-1.293^{*} \\
(0.743)\end{array}$ & $\begin{array}{c}-1.500^{* *} \\
(0.721)\end{array}$ & $\begin{array}{c}-1.742^{* *} \\
(0.718)\end{array}$ \\
\hline IndustryClock & $\begin{array}{c}-0.309^{* * *} \\
(0.060)\end{array}$ & $\begin{array}{c}-0.308^{* * *} \\
(0.060)\end{array}$ & $\begin{array}{c}-0.433^{* * *} \\
(0.074)\end{array}$ & $\begin{array}{c}-0.379^{* * *} \\
(0.065)\end{array}$ & $\begin{array}{c}-0.352^{* * *} \\
(0.064)\end{array}$ \\
\hline ClassClock & $\begin{array}{c}-0.092^{* *} \\
(0.041)\end{array}$ & $\begin{array}{c}-0.090^{* *} \\
(0.041)\end{array}$ & $\begin{array}{c}-0.097^{* *} \\
(0.042)\end{array}$ & $\begin{array}{c}-0.151^{* * *} \\
(0.045)\end{array}$ & $\begin{array}{c}-0.171^{* * *} \\
(0.044)\end{array}$ \\
\hline SalesGrowthInClass & $\begin{array}{c}0.000 \\
(0.000)\end{array}$ & $\begin{array}{c}0.000 \\
(0.000)\end{array}$ & $\begin{array}{c}0.000 \\
(0.000)\end{array}$ & $\begin{array}{c}0.000 \\
(0.000)\end{array}$ & $\begin{array}{c}0.000 \\
(0.000)\end{array}$ \\
\hline ClassDensity & $\begin{array}{l}0.137^{* * *} \\
(0.032)\end{array}$ & $\begin{array}{l}0.136 * * * \\
(0.032)\end{array}$ & $\begin{array}{l}0.142^{* * *} \\
(0.033)\end{array}$ & $\begin{array}{l}0.111^{* * *} \\
(0.032)\end{array}$ & $\begin{array}{l}0.108^{* * *} \\
(0.032)\end{array}$ \\
\hline ClassDensitySq & $\begin{array}{c}-0.003^{* * *} \\
(0.001)\end{array}$ & $\begin{array}{c}-0.003^{* * *} \\
(0.001)\end{array}$ & $\begin{array}{c}-0.003^{* * *} \\
(0.001)\end{array}$ & $\begin{array}{c}-0.002^{* * *} \\
(0.001)\end{array}$ & $\begin{array}{c}-0.002^{* * *} \\
(0.001)\end{array}$ \\
\hline SalesGrowthInCurrentClasses & & $\begin{array}{r}-0.021^{*} \\
(0.011)\end{array}$ & $\begin{array}{c}-0.011 \\
(0.007)\end{array}$ & $\begin{array}{c}-0.025 \\
(0.017)\end{array}$ & $\begin{array}{c}-0.025 \\
(0.017)\end{array}$ \\
\hline FirmAge & & & $\begin{array}{l}0.294^{* * *} \\
(0.062)\end{array}$ & $\begin{array}{l}0.182^{* * *} \\
(0.042)\end{array}$ & $\begin{array}{c}0.183^{* * *} \\
(0.042)\end{array}$ \\
\hline SamePPM & & & & $\begin{array}{l}0.661^{* * *} \\
(0.122)\end{array}$ & $\begin{array}{l}0.494^{* * *} \\
(0.148)\end{array}$ \\
\hline SameDPI & & & & $\begin{array}{l}0.991^{* * *} \\
(0.097)\end{array}$ & $\begin{array}{l}0.842^{* * *} \\
(0.129)\end{array}$ \\
\hline Neighbor & & & & & $\begin{array}{l}0.498^{* *} \\
(0.225)\end{array}$ \\
\hline HPDum & & & $\begin{array}{c}0.466 \\
(0.302)\end{array}$ & $\begin{array}{l}1.212^{* * *} \\
(0.256)\end{array}$ & $\begin{array}{l}1.394^{* * *} \\
(0.243)\end{array}$ \\
\hline$H P *$ SalesGrowthInClass & & & $\begin{array}{c}0.000 \\
(0.000)\end{array}$ & $\begin{array}{c}0.000 \\
(0.000)\end{array}$ & $\begin{array}{c}0.000 \\
(0.000)\end{array}$ \\
\hline$H P *$ SalesGrowthInCurrentClasses & & & $\begin{array}{c}-0.459 * * * \\
(0.060)\end{array}$ & $\begin{array}{c}-0.418^{* * *} \\
(0.058)\end{array}$ & $\begin{array}{c}-0.435^{* * *} \\
(0.059)\end{array}$ \\
\hline$H P * S a m e P P M$ & & & & $\begin{array}{c}-0.447^{* * *} \\
(0.118)\end{array}$ & $\begin{array}{c}-0.093 \\
(0.140)\end{array}$ \\
\hline$H P *$ SameDPI & & & & $\begin{array}{c}-0.589 * * * \\
(0.099)\end{array}$ & $\begin{array}{c}-0.149 \\
(0.140)\end{array}$ \\
\hline$H P *$ Neighbor & & & & & $\begin{array}{c}-1.267^{* * *} \\
(0.242)\end{array}$ \\
\hline$N^{\mathrm{a}}$ & 11,342 & 11,342 & 11,342 & 11,342 & 11,342 \\
\hline No. of failures & 205 & 205 & 205 & 205 & 205 \\
\hline No. of subjects (firm-classes) & 2,248 & 2,248 & 2,248 & 2,248 & 2,248 \\
\hline No. of clusters in S.E. & 120 & 120 & 120 & 120 & 120 \\
\hline Log-pseudolikelihood & -513.42 & -510.08 & -470.53 & -414.77 & -411.10 \\
\hline
\end{tabular}

Notes. Piecewise exponential hazard-rate estimation with robust standard errors. Unit of observation: firm-class year $\left({ }^{*} p<0.10,{ }^{* *} p<0.05,{ }^{* * *} p<0.01\right)$.

${ }^{a}$ Includes all firm-class years for which firm $i$ was at risk of entering class $j$ during year $t$. Once firm $i$ enters class $j$, it is not at risk of entering again. Firm $i$ is not at risk of entering a new class until it is competing in at least one segment in the industry. Thus, we exclude the pioneering entry of each firm into the industry.

class, and industry characteristics, the dominant firm is more likely to enter a new class as sales growth in its existing classes falls.

To test Hypothesis 2, we examine the variables SameDPI and $H P *$ SameDPI, which measure the extent to which a firm enters new product segments in the same DPI range as its current products. Recall that Hypothesis 2 applied to all firms seeking new markets. The coefficient on SameDPI is positive, with the underlying hazard ratio indicating that a firm 
Figure 4 HP Printer Units Shipped by Year and Class (Data Not Collected Prior to 1987)

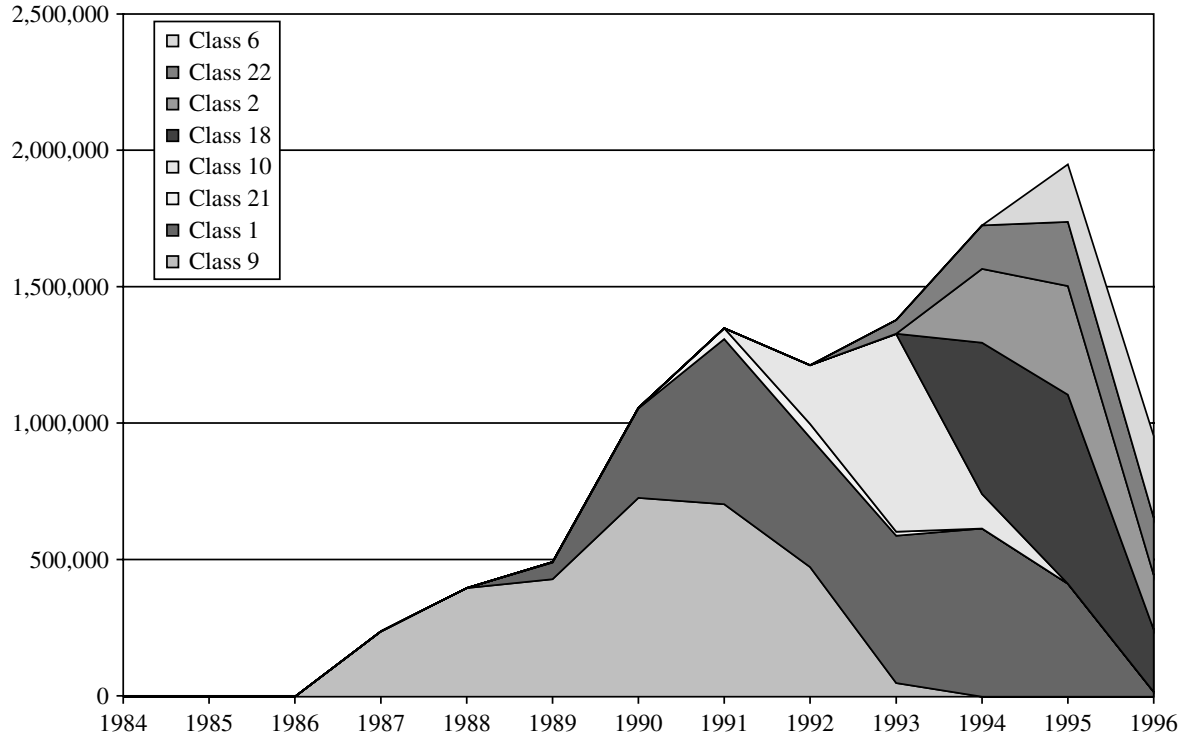

is $132 \%$ more likely to pursue entry into segments within its current DPI ranges than in other DPI ranges. In Model 5, the coefficient on $H P *$ SameDPI is not statistically different from zero. ${ }^{11}$ As expected, HP shows no greater or lesser tendency to stay within its DPI range than fringe firms. The coefficients for SamePPM and HP * SamePPM exhibit the same patterns of sign, magnitude, and significance, indicating that firms are also more likely to enter segments in the same PPM range as their existing segments. However, the coefficient for SameDPI is significantly larger than the coefficient for SamePPM. Our operationalization of Hypothesis 2 anticipated that firms would not only be likely to enter segments in the same DPI range but also more likely to enter these segments than those in the same PPM range; we therefore interpret the above as evidence supporting this hypothesis.

Our examination of Hypothesis 3 focuses on the coefficients on Neighbor and HP $*$ Neighbor. The coefficient on Neighbor is large, positive, and statistically significant. A fringe firm is $104 \%$ more likely to enter an adjacent segment than a segment further away. Consistent with Hypothesis 3A, fringe firms choose to enter adjacent markets, presumably to take full advantage of opportunites to exploit existing technological assets or scope economies or both. However, the coefficient on $H P *$ Neighbor indicates that $\mathrm{HP}$ follows the opposite strategy. It is $71 \%$ less likely than other firms to enter adjacent segments than segments further away. Combining the direct and interactive effects, the model demonstrates that HP is $41 \%$ less likely to pursue adjacent segments than more

\footnotetext{
${ }^{11}$ In Model 4, this coefficient is statistically significant and negative, but this effect goes away once we control for entry into neighboring classes. This underscores HP's aversion to entering adjacent classes.
}

distant ones. This is consistent with Hypothesis 3B, which suggests that the dominant firm will skip adjacent segments to avoid cannibalization of current products.

The remaining results from Table 2 also point to several other factors influencing a firm's entry decision. Consistent with prior research, we find that density in a class has an inverted-U relationship with the hazard of entry into that class. We also find that industry age and class age each have a negative relationship with entry. ${ }^{12}$ FirmAge has a positive coefficient, indicating that older firms are more likely to diversify into new segments, while the current sales growth in a focal segment (SalesGrowthInClass) has little relationship with the probability of entry into that segment.

4.1.2. Effect of Dominant Firm Entry on Price and Sales. Hypotheses 4 and 5 predict that individual segments will experience an accelerated price decline and sales takeoff because of the dominant firm's entry. First, we examine the price trends with descriptive data. Figure 5 presents the price trends in a representative class, both for $\mathrm{HP}$ and for fringe firms, and before HP and after HP. Note that there seems to be a declining trend in price over time. HP's entry, however, is associated with a step-function decrease in the price. (Graphs for all segments, available from the authors, show patterns that largely conform to Figure 5.) Table 3 presents the results of a statistical test of these patterns. Model 1 provides a baseline OLS estimation with class random effects.

\footnotetext{
${ }^{12}$ When we include IndustryClockSq and ClassClockSq, all of the clocks are significant. No other coefficients change in sign, magnitude, or significance.
} 
Figure 5 Price Evolution in Class 22 (HP Enters 1993)

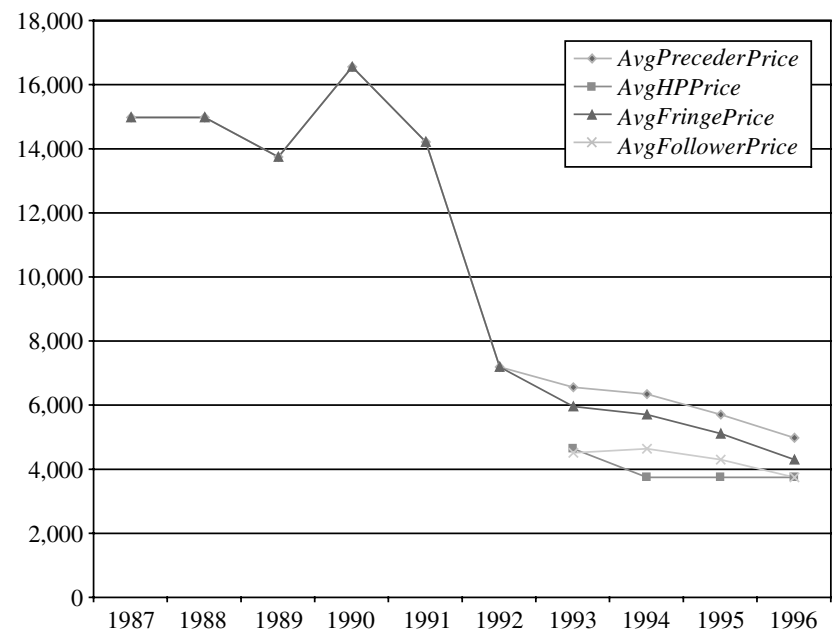

Model 2 adds ClassDensity; the addition of this variable does not improve the fit of the model. ${ }^{13}$ Model 3 adds HPInClass and HPClock to identify the effect of the dominant firm's entry into the segment. Given the construction of these two variables (as described in Table 1), HPInClass captures the initial (shift) effect of $\mathrm{HP}^{\prime}$ 's entry on segment price, while HPClock captures how prices change in the segment (slope) as HP stays in the segment. This model is a significant improvement over the first two.

ClassClock has a negative and statistically significant coefficient, indicating that the price of a laser printer in a class falls over time. This result is consistent with the general literature on technology goods witnessing price declines over time. Consistent with the prediction of Hypothesis 4, HPInClass has a negative coefficient that is statistically significant, indicating that HP's presence in a segment is associated with lower prices. The magnitude of this coefficient is roughly 2.5 times the magnitude of the ClassClock coefficient, meaning that the entry of HP into a segment is associated with a price drop that would take more than 2.5 years to occur in $\mathrm{HP}^{\prime} \mathrm{s}$ absence.

HPClock has a positive and statistically significant coefficient that is roughly $40 \%$ of the magnitude of ClassClock's coefficient (in absolute value terms). This indicates that price, after plummeting upon HP's entry, declines more gradually over time than it would in the absence of HP. Although there is little extant theory about the long-term effect of dominant firm entry on prices, this pattern of steep initial price drop and slower long-term rate of decline is consistent with some prior empirical research concerning entry by a low-cost player in the airline industry (Goolsbee and

\footnotetext{
${ }^{13}$ ClassDensitySq is omitted because there is no theoretical rationale for a nonlinear relationship between number of firms and price. Its inclusion does not change the reported results.
}

Table 3 The Effect of Dominant Firm Entry on Price Within a Class

\begin{tabular}{lcccc}
\hline & \multicolumn{4}{c}{ Model } \\
\cline { 2 - 5 } Variable & $(1)$ & $(2)$ & $(3)$ & $(4)$ \\
\hline ClassClock & $-371.16^{* * *}$ & $-360.21^{* * *}$ & $-466.33^{* * *}$ & $-463.78^{* * *}$ \\
& $(23.00)$ & $(27.39)$ & $(40.95)$ & $(40.93)$ \\
ClassDensity & & -6.79 & 12.82 & 11.12 \\
& & $(9.11)$ & $(10.37)$ & $(10.38)$ \\
HPInClass & & & $-1,139.40^{* * *}$ & $-1,026.87^{* * *}$ \\
& & & $(289.01)$ & $(291.69)$ \\
HPClock & & & $191.63^{* * *}$ & $176.08^{* * *}$ \\
& & & $(50.08)$ & $(50.33)$ \\
HPDum & & & $-1,497.44^{* * *}$ \\
& & & & $(541.20)$ \\
HPDum* HPClock & & & & $258.38^{* * *}$ \\
Constant & $6,232.70^{* * *}$ & $6,255.04^{* * *}$ & $6,715.87^{* * *}$ & $(94.24)$ \\
& $(555.37)$ & $(567.80)$ & $(594.81)$ & $\left(595.43^{* *}\right.$ \\
$N$ & 3,210 & 3,210 & 3,210 & 3,210 \\
No. of groups & 23 & 23 & 23 & 23 \\
Random effects & Class & Class & Class & Class \\
Wald chi-square & $260.43^{* * *}$ & $261.15^{* * *}$ & $288.47^{* * *}$ & $297.23^{* * *}$ \\
$R^{2}$ & 0.04 & 0.03 & 0.03 & 0.03 \\
\hline
\end{tabular}

Notes. OLS regression estimation with random effects (dependent variable: Price $\left._{k j t}\right)$. Unit of observation: model-class year $\left({ }^{*} p<0.10,{ }^{* *} p<0.05\right.$, $\left.{ }^{* * *} p<0.01\right)$.

Syverson 2005). ${ }^{14}$ This one-time drop and subsequent lower rate of decline is also plausibly consistent with circumstances in which Cournot competition between high-cost firms is supplanted by Stackelberg competition between a high- and a low-cost firm for sufficiently different levels of cost between high- and low-cost firms. ${ }^{15}$

Having obtained substantial traction on Hypothesis 4, we extend our analysis to examine HP's prices relative to other firms in the segment. In Model 4, we introduce two new variables-HPDum and HPDumClock - to determine whether HP's printers are priced differently than those of fringe firms. HPDum is statistically significant and negatively related to price, with a coefficient of nearly $-1,500$. HPDumClock is positively related to price, with a coefficient of 258. This implies that when HP first enters a segment, its printers are priced nearly $\$ 1,500$ below the average printer in that segment. Over time, this price gap shrinks. This result is consistent with our broader theory and with the price graph in Figure 5; as current fringe firms lower prices, and are replaced by new fringe firms that follow HP into the segment, we would expect the price differential between HP and the average fringe rival to shrink.

\footnotetext{
${ }^{14}$ Goolsbee and Syverson (2005) find that airfare prices on a route decline rapidly in anticipation of, and at the time of, entry by Southwest into the market. After the drop at entry, prices then exhibit a lower rate of decline.

${ }^{15}$ Analytical results demonstrating this are available from the authors.
} 
Figure 6 Firm Entry and Sales Takeoff in the Laser Printer Industry (Enter Industry: All Classes Combined)

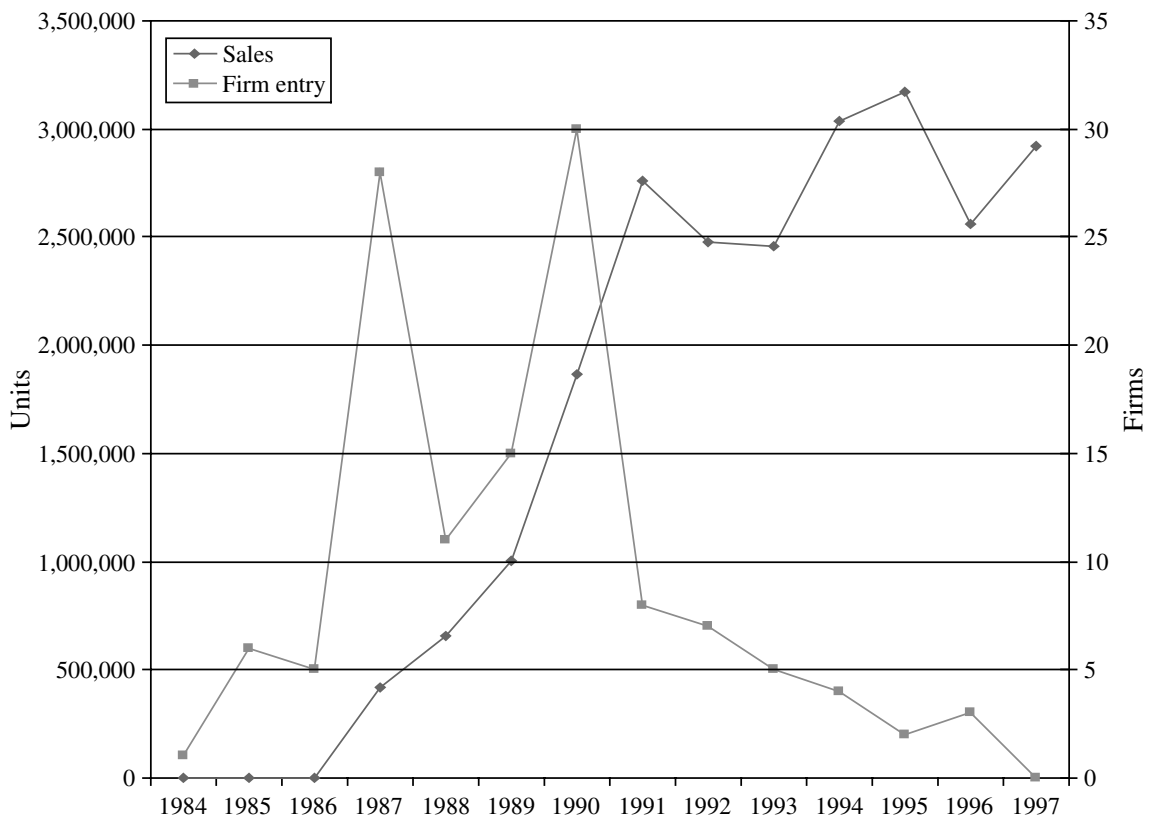

We now turn to Hypothesis 5, which predicts that the dominant firm's entry into a class will create a substantial increase in sales in the class. Figure 6 shows that, as a single market, the desktop laser printer industry sales pattern appears similar to that found in other industries (Agarwal and Bayus 2002). Thus, results from this industry are not likely to be idiosyncratic to laser printers. Figure 7 shows similar information for a single class, and also indicates the year of entry by HP. HP's entry appears to precede both the bulk of fringe firm entry and the takeoff in sales. (Graphs for all segments, available from the authors, show patterns that largely conform to Figure 7.) Thus, although this class appears to exhibit a pattern of entry and sales that is consistent with prior research on the sales takeoff, inclusion of information on $\mathrm{HP}^{\prime} \mathrm{s}$ entry raises the possibility that both fringe firm entry and sales takeoff are triggered by dominant firm entry. To explore this further, Table 4 describes the magnitude of the sales takeoff across each class. This table shows that classes that experience HP entry have much higher peak sales (always occurring after HP entry) than those that do not. Together, Figure 7 and Table 4 suggest that the existence and timing of sales takeoff coincides with the entry of the dominant firm. We explore this further through regression analysis in Table 5.

Model 1 in Table 5 provides a baseline OLS estimation with class random effects; Models 2-4 include additional variables. Because the coefficients are relatively stable across models and Model 4 offers the best fit, we focus our discussion on that model. ClassClock has a positive coefficient and ClassClockSq has a negative coefficient, indicating that sales rise and then fall as a class ages, with the inflection point around 6.6 years. HPInClass has a positive, significant, and extremely large coefficient, while HPClock and HPClockSq are not significant. This indicates that $\mathrm{HP}^{\prime}$ s entry into a class is associated with an astounding 3,500\% increase in sales, controlling for other factors. This dramatic increase in sales is consistent with descriptive data found in Figure 7 and Table 4 and also with Hypothesis 5.

4.1.3. The "Churn." In our final two predictions, Hypotheses 6 and 7, we examine the churn in the segment created by the dominant firm's entry. We predict that incumbent fringe firms will tend to exit the segment when the dominant firm enters, while another set of fringe firms will enter the segment and compete in the shadow of the dominant firm. Table 6 presents the results of a negative binomial estimation of entry by fringe firms into each class as a function of HP's presence, among other characteristics. Although Models 1-4 provide nonnested specifications, they generate coefficients that are remarkably similar across models. We therefore focus our discussion on Model 4. In this model, HPInClass has a positive and statistically significant coefficient. After controlling for basic industry and class characteristics, HP's presence in a class is positively associated with fringe firm entry into that class, as predicted by Hypothesis 6. In addition, consistent with prior research, we find that ClassDensity and ClassDensitySq exhibit positive and negative associations, respectively, with entry into a class.

Finally, we examine the effect of dominant firm entry on fringe firm exit. Hypothesis 7 predicts that 
Figure 7 Class 21-Dominant Firm Entry, Fringe Firm Entry, and Sales Takeoff (HP Enters 1989)

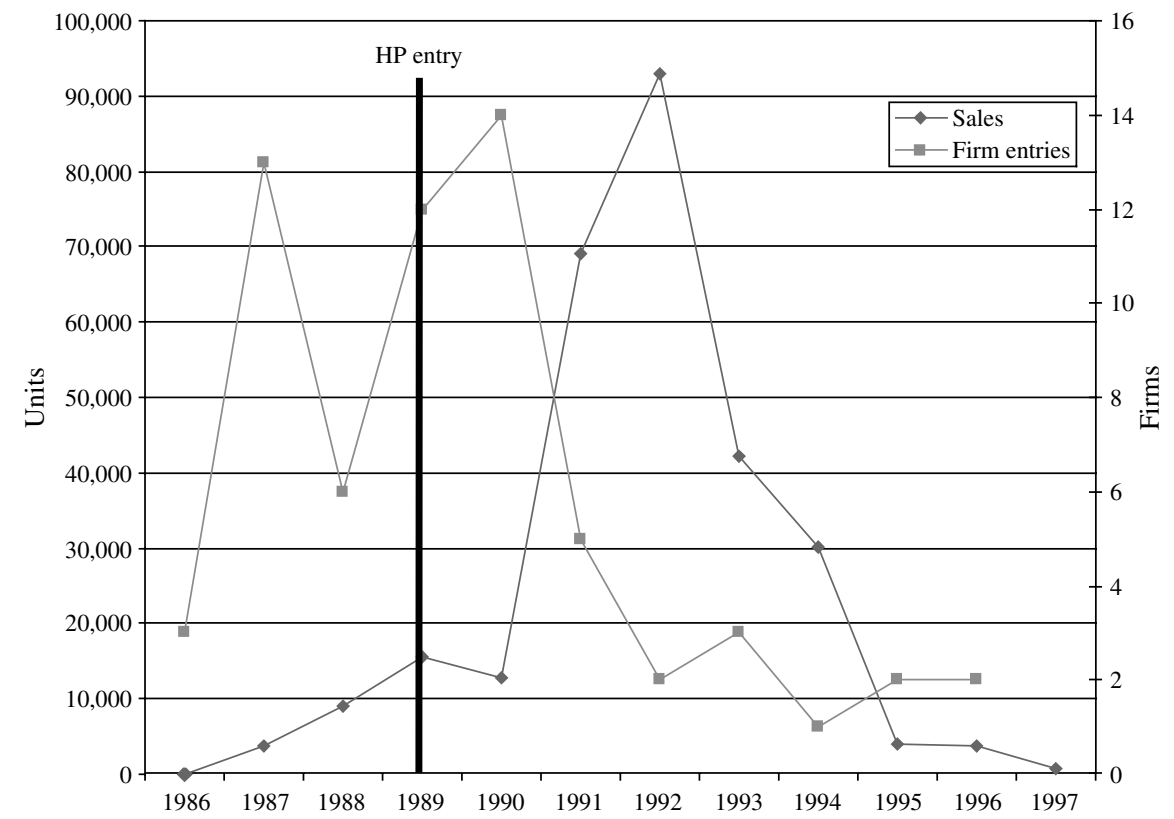

after a dominant firm enters a segment, fringe firms that preceded it into the segment will be more likely to exit than fringe firms that follow it into the segment, ceteris paribus. Table 7 presents the results of a piecewise exponential hazard rate model with robust standard errors clustered on the firm to test this prediction. Model 1 provides a standard baseline model. IndustryClock is negatively related to exit, while ClassClock is positively related to exit. This suggests that exit rates from an industry decline over time, but firms accelerate their exit from old classes as new classes open up (or as the dominant firm expands into additional segments). Surprisingly, the density of firms in a class exhibits an inverted- $U$ relationship with exit, which is contrary to the conventional

Table 4 Peak Annual Sales by Class

\begin{tabular}{|c|c|c|c|c|c|c|}
\hline \multicolumn{4}{|c|}{ Classes that HP enters, 1984-1996 } & \multirow{2}{*}{\multicolumn{3}{|c|}{$\begin{array}{c}\text { Classes that HP does } \\
\text { not enter by } 1996\end{array}$}} \\
\hline \multirow[b]{2}{*}{ Class } & \multirow[b]{2}{*}{ Peak sales } & \multirow[b]{2}{*}{ Peak year } & \multirow{2}{*}{$\begin{array}{l}\text { Year of } \\
\text { HP entry }\end{array}$} & & & \\
\hline & & & & Class & Peak sales & Peak year \\
\hline 9 & $1,038,626$ & 1990 & 1984 & 5 & 396,054 & 1995 \\
\hline 1 & 981,565 & 1991 & 1989 & 13 & 244,958 & 1991 \\
\hline 18 & 789,467 & 1995 & 1992 & 14 & 127,300 & 1993 \\
\hline 10 & 754,500 & 1993 & 1992 & 17 & 74,911 & 1991 \\
\hline 6 & 518,829 & 1996 & 1995 & 7 & 25,650 & 1996 \\
\hline 2 & 516,392 & 1995 & 1993 & 11 & 18,570 & 1996 \\
\hline 22 & 254,579 & 1995 & 1993 & 20 & 9,610 & 1994 \\
\hline 24 & 119,645 & 1996 & 1996 & 12 & 8,065 & 1995 \\
\hline \multirow[t]{6}{*}{21} & 93,054 & 1992 & 1989 & 23 & $<5,000$ & 1994 \\
\hline & & & & 19 & $<5,000$ & 1995 \\
\hline & & & & 3 & $<5,000$ & 1992 \\
\hline & & & & 4 & $<5,000$ & 1993 \\
\hline & & & & 15 & $<5,000$ & 1996 \\
\hline & & & & 16 & $<5,000$ & 1996 \\
\hline
\end{tabular}

result in populationwide studies ${ }^{16}$ However, firm age exhibits an inverted-U relationship with exit, consistent with a liability of adolescence that has also been found in prior literature. Other factors do not have a significant effect on fringe firm exit.

Model 2 adds HPPreceder $r_{i j}$, which identifies firms that precede HP into a class. HPPreceder has a significant and positive coefficient, indicating that firms that precede HP into a class have a $107 \%$ higher rate of exit than firms that follow HP. Note, however, that this variable does not vary with time; hence, it does not distinguish between time periods before the entry of HP and time periods after its entry. We turn to the heart of the question in Model 3 where we replace HPPreceder with two time-varying variables, HPPrecederBeforeHPEntry $y_{i j t}$ and HPPrecederAfterHPEntry $y_{i j t}$. These variables permit us to observe the effect of HP's entry on fringe firms that precede it into a class, and to compare before and after exit rates to each other as well as to the unobserved category of fringe firms that follow HP into a class. HPPrecederBeforeHPEntry has a positive coefficient, but it is not significant. Exit rates for fringe firms in a segment that $\mathrm{HP}$ has not yet entered are statistically indistinguishable from those for fringe firms that follow HP into a segment. In contrast, HPPrecederAfterHPEntry has a positive, significant coefficient of substantial magnitude; after HP enters a segment, fringe firms that preceded it are $128 \%$ more likely to exit than fringe

${ }^{16}$ This may reflect the short post-HP-entry time period for several classes in our sample. If we observe a swarm of followers in the short term but do not observe a longer term segment-specific shakeout, this could drive the result. 
Table 5

The Effect of Dominant Firm Entry on Sales Within a Class

\begin{tabular}{lcccc}
\hline & \multicolumn{4}{c}{ Model } \\
\cline { 2 - 5 } Variable & $(1)$ & $(2)$ & $(3)$ & $(4)$ \\
\hline ClassClock & $0.767^{* *}$ & $2.923^{* * *}$ & $2.686^{* * *}$ & $2.806^{* * *}$ \\
& $(0.342)$ & $(0.573)$ & $(0.591)$ & $(0.504)$ \\
ClassClockSq & & $-0.197^{* * *}$ & $-0.193^{* * *}$ & $-0.205^{* * *}$ \\
& & $(0.080)$ & $(0.082)$ & $(0.078)$ \\
ClassDensity & $0.121^{* *}$ & $0.074^{*}$ & -0.004 & 0.002 \\
& $(0.051)$ & $(0.045)$ & $(0.046)$ & $(0.047)$ \\
HPInClass & & & $3.312^{* *}$ & $3.889^{* *}$ \\
& & & $(1.494)$ & $(2.017)$ \\
HPClock & & & 0.093 & -0.273 \\
& & & $(0.185)$ & $(0.183)$ \\
HPClockSq & & & & 0.035 \\
& & & -0.321 & -0.515 \\
Constant & $3.766^{* * *}$ & -0.371 & $(1.389)$ & $(1.379)$ \\
& $(1.503)$ & $(1.410)$ & 163 & 163 \\
$N$ & 163 & 163 & 23 & 23 \\
No. of groups & 23 & 23 & Class & Class \\
Random effects & Class & Class & $180.80^{* * *}$ & $181.56^{* * *}$ \\
Wald chi-square & $61.14^{* * *}$ & $145.79^{* * *}$ & 0.49 & 0.49 \\
$R^{2}$ & 0.26 & 0.39 & \\
\hline
\end{tabular}

Notes. OLS regression estimation with random effects (dependent variable: UnitSales $\left._{j t}\right)$. Unit of observation: class year $\left({ }^{*} p<0.10,{ }^{* *} p<0.05,{ }^{* * *} p<\right.$ $0.01)$.

firms that followed it, after controlling for firm age as well as key class and industry characteristics. This is consistent with the exit prediction of Hypothesis 7incumbent fringe firms will exit after the entry of the dominant firm, while firms that enter with or after the dominant firm will be less likely to exit, ceteris paribus. Indeed, the combination of Hypotheses 6 and 7 generate churn in the industry.

Which fringe firms tend to precede HP into classes and which tend to follow? It is beyond the scope of this paper to explore this in detail. However, initial difference-of-means tests on the preceder versus follower subsamples (available from the authors) reveal differences between the two types of firms on four characteristics for which we have data: compared to followers, preceders are less likely to be members of the Fortune 1000, less likely to be vertically integrated into engine production, less likely to win awards for their printers, and boast smaller patent portfolios. This pattern is broadly consistent with an assumption that followers are better suited to compete in a post-HP environment where competition depends in part on size. It is also consistent with an alternate assumption that larger firms tend to delay entry into a new segment until uncertainty associated with that segment is resolved (Mitchell 1989). We leave further exploration of fringe firm characteristics as one of the most compelling areas for future research, and we turn to alternative explanations below.

4.1.4. Alternative Hypotheses. Our theory proposes that the dominant firm can create changes in both the supply curve and demand curve, which in
Table 6 The Effect of HP's Presence in a Class on Fringe Firm Entry

\begin{tabular}{|c|c|c|c|c|}
\hline \multirow[b]{2}{*}{ Variable } & \multicolumn{4}{|c|}{ Model } \\
\hline & (1) & (2) & (3) & (4) \\
\hline IndustryClock & $\begin{array}{c}-0.064 \\
(0.063)\end{array}$ & $\begin{array}{c}-0.089^{* *} \\
(0.043)\end{array}$ & $\begin{array}{c}-0.037 \\
(0.060)\end{array}$ & $\begin{array}{c}-0.074 \\
(0.057)\end{array}$ \\
\hline IndustryDensity & $\begin{array}{c}0.009 \\
(0.013)\end{array}$ & & $\begin{array}{r}-0.015 \\
(0.015)\end{array}$ & $\begin{array}{r}-0.010 \\
(0.014)\end{array}$ \\
\hline IndustryDensitySq & $\begin{array}{c}-0.000 \\
(0.000)\end{array}$ & & $\begin{array}{c}0.000 \\
(0.000)\end{array}$ & $\begin{array}{c}0.000 \\
(0.000)\end{array}$ \\
\hline ClassClock & & $\begin{array}{c}-0.115 \\
(0.072)\end{array}$ & $\begin{array}{c}-0.127 \\
(0.075)\end{array}$ & $\begin{array}{c}-0.100 \\
(0.077)\end{array}$ \\
\hline ClassDensity & & $\begin{array}{l}0.120^{* * *} \\
(0.027)\end{array}$ & $\begin{array}{l}0.126^{* * * *} \\
(0.031)\end{array}$ & $\begin{array}{l}0.093^{* * *} \\
(0.030)\end{array}$ \\
\hline ClassDensitySq & & $\begin{array}{c}-0.002^{* * * *} \\
(0.001)\end{array}$ & $\begin{array}{c}-0.002^{* * *} \\
(0.001)\end{array}$ & $\begin{array}{c}-0.002^{* * *} \\
(0.001)\end{array}$ \\
\hline SalesGrowthInClass & & $\begin{array}{c}0.000 \\
(0.000)\end{array}$ & $\begin{array}{c}0.000 \\
(0.000)\end{array}$ & $\begin{array}{c}0.000 \\
(0.000)\end{array}$ \\
\hline HPInClass & & & & $\begin{array}{l}0.603^{* * * *} \\
(0.156)\end{array}$ \\
\hline Constant & $\begin{array}{l}1.369^{* * *} \\
(0.311)\end{array}$ & $\begin{array}{l}1.469^{* * *} \\
(0.339)\end{array}$ & $\begin{array}{l}1.683^{* * * *} \\
(0.312)\end{array}$ & $\begin{array}{l}1.652^{* *} \\
(0.349)\end{array}$ \\
\hline$N$ & 139 & 139 & 139 & 139 \\
\hline olikelihood & -290.75 & -274.99 & -274.08 & -266.51 \\
\hline Wald chi-square & 2.16 & $44.75^{* * *}$ & $55.50^{* * *}$ & $66.62^{* * *}$ \\
\hline
\end{tabular}

Notes. Negative binomial estimation with robust standard errors (dependent variable: EntryCount $\left.t_{j t}\right)$. Unit of observation: class year $\left({ }^{*} p<0.10,{ }^{* *} p<\right.$ $\left.0.05,{ }^{* * *} p<0.01\right)$.

turn creates a wave of entry (and exit) by fringe firms, a price decline, and a sales takeoff. There are four alternative hypotheses that might explain the same results. First, it could be that the sales takeoff is generated solely by the dominant firm shifting the supply curve but having no effect on the demand curve. Second, it could be that the fringe firms that enter contemporaneously with the dominant firm cause these effects; the dominant firm entry is merely correlated with these effects. Third, it could be that the sales takeoff is caused by exogenous factors, and that the dominant firm is a particularly good forecaster of which segments will experience a takeoff. Fourth, technological change could enable provision of printers at low cost at a point in time, and this triggers entry by a swarm of firms (including HP) as well as the price decline and sales takeoff; this could be particularly pronounced if the demand curve is highly inelastic at high prices and is highly elastic at lower prices. ${ }^{17}$

Although we cannot conclusively rule out all of these alternative hypotheses, we believe that the preponderance of evidence as found in our data and analysis supports our explanation for the laser printer industry. ${ }^{18}$ We base our interpretation primarily on six

\footnotetext{
${ }^{17}$ We thank an anonymous referee for suggesting the fourth alternative explanation.

${ }^{18}$ We address these at greater length in the electronic appendix.
} 
Table 7 Effect of HP Entry on Fringe Firm Exit from Class ("HP Preceders" vs. "HP Followers")

\begin{tabular}{|c|c|c|c|}
\hline \multirow[b]{2}{*}{ Variable } & \multicolumn{3}{|c|}{ Model } \\
\hline & (1) & (2) & (3) \\
\hline Time piece 1 & $\begin{array}{c}-7.279^{* * * *} \\
(1.192)\end{array}$ & $\begin{array}{c}-7.805^{* * *} \\
(1.228)\end{array}$ & $\begin{array}{c}-7.597^{\text {*** }} \\
(1.215)\end{array}$ \\
\hline Time piece 2 & $\begin{array}{c}-3.401^{* * *} \\
(1.125)\end{array}$ & $\begin{array}{c}-3.842^{* * *} \\
(1.162)\end{array}$ & $\begin{array}{c}-3.631^{* * * *} \\
(1.171)\end{array}$ \\
\hline IndustryClock & $\begin{array}{c}-0.431^{* * *} \\
(0.118)\end{array}$ & $\begin{array}{c}-0.426^{* * *} \\
(0.120)\end{array}$ & $\begin{array}{c}-0.439 * * * \\
(0.121)\end{array}$ \\
\hline ClassClock & $\begin{array}{l}0.301^{* * *} \\
(0.109)\end{array}$ & $\begin{array}{l}0.309^{* * *} \\
(0.112)\end{array}$ & $\begin{array}{l}0.320^{* * *} \\
(0.113)\end{array}$ \\
\hline SalesGrowthInClass & $\begin{array}{c}0.081^{*} \\
(0.047)\end{array}$ & $\begin{array}{c}0.115^{* *} \\
(0.053)\end{array}$ & $\begin{array}{l}0.107^{* *} \\
(0.053)\end{array}$ \\
\hline ClassDensity & $\begin{array}{c}-0.001^{*} \\
(0.000)\end{array}$ & $\begin{array}{c}-0.002^{* *} \\
(0.001)\end{array}$ & $\begin{array}{c}-0.002^{* *} \\
(0.001)\end{array}$ \\
\hline ClassDensitySq & $\begin{array}{c}-0.000 \\
(0.001)\end{array}$ & $\begin{array}{c}-0.001 \\
(0.003)\end{array}$ & $\begin{array}{c}-0.000 \\
(0.001)\end{array}$ \\
\hline FirmAge & $\begin{array}{l}0.607^{* * *} \\
(0.185)\end{array}$ & $\begin{array}{l}0.589^{* * * *} \\
(0.186)\end{array}$ & $\begin{array}{l}0.575^{* * *} \\
(0.185)\end{array}$ \\
\hline FirmAgeSq & $\begin{array}{c}-0.057^{* * *} \\
(0.018)\end{array}$ & $\begin{array}{c}-0.056^{* * * *} \\
(0.018)\end{array}$ & $\begin{array}{c}-0.055^{* * *} \\
(0.018)\end{array}$ \\
\hline NumClasses & $\begin{array}{c}0.031 \\
(0.078)\end{array}$ & $\begin{array}{c}0.031 \\
(0.074)\end{array}$ & $\begin{array}{c}0.030 \\
(0.073)\end{array}$ \\
\hline Neighbor & $\begin{array}{c}-0.129 \\
(0.294)\end{array}$ & $\begin{array}{c}-0.138 \\
(0.297)\end{array}$ & $\begin{array}{c}-0.139 \\
(0.298)\end{array}$ \\
\hline HPPreceder & & $\begin{array}{l}0.730^{* *} \\
(0.327)\end{array}$ & \\
\hline HPPrecederBeforeHPEntry & & & $\begin{array}{c}0.375 \\
(0.640)\end{array}$ \\
\hline HPPrecederAfterHPEntry & & & $\begin{array}{l}0.823^{* *} \\
(0.348)\end{array}$ \\
\hline$N^{\mathrm{a}}$ & 1,931 & 1,931 & 1,931 \\
\hline No. of failures & 65 & 65 & 65 \\
\hline No. of subjects (firm classes) & 395 & 395 & 395 \\
\hline No. of clusters in std. errors & 395 & 395 & 395 \\
\hline Log-pseudolikelihood & -124.15 & -122.01 & -121.83 \\
\hline
\end{tabular}

Notes. Piecewise exponential hazard-rate estimation with robust standard errors. Unit of observation: firm-class year $\left({ }^{*} p<0.10,{ }^{* *} p<0.05,{ }^{* * *} p<\right.$ 0.01).

ancludes all firm-class years for which firm $i$ was at risk of exiting class $j$ during year $t$. Includes all classes whether or not HP entered during the sample frame. For classes in which HP never enters, $H P P$ receder $i j=1$, and for all $t$, HPPrecederBeforeHPEntry ${ }_{i j t}=1$. This assumes that these classes are at similar risk of HP entry as those that experienced HP entry. We also estimate these models after restricting our sample to include only classes that HP entered during our sample frame. The results of these models, available from the authors, are qualitatively the same as those above.

facts. First, HP often enters classes that are adjacent to, and more technologically challenging than, classes that it skips (e.g., segment 18 versus segment 14). Second, fringe firms that precede HP into a class tend to exit after HP enters. Third, HP entry into a new segment is triggered by slowing growth in HP's existing classes. Fourth, Table 6 indicates that after controlling for HP, ClassDensity has no significant association with sales. Fifth, the sheer size of the sales takeoff after dominant firm entry is immense- $35 \times$ according to our estimation. Sixth, Figure 5 shows that fringe firms that follow HP price substantially below those that precede HP.
The first two facts work against the fourth alternative explanation. If technology has advanced sufficiently to support low-cost production in class 18, then it should also support low-cost production in the similar but less complex Class 14 . Yet we do not see a wave of entry into that class in the absence of HP, and peak sales in Class 18 exceed those of Class 14 by a factor of five. It is difficult to reconcile this with an exogenous-technology explanation. Further, if this is explained by exogenous technological change, it is difficult to see why incumbent fringe firms should exit as the takeoff occurs. As far as the good-forecaster explanation, the third fact suggests that for this to be correct, there would have to be systematic negative correlation between a sales takeoff in a new segment and a decline in sales in the existing segments-in other words, each time HP experiences a decline in existing segments, another segment is about to take off. While this is theoretically possible, it is empirically unlikely.

Fact four suggests that the sales takeoff is not driven by fringe firms that enter with HP. ClassDensity is positively associated with increased sales when variables for HP's entry are omitted but its coefficient becomes insignificant when the model includes HP variables. This implies that HP's presence in a class, and not the number of fringe firms, sparks the sales takeoff. As for the possibility that the sales takeoff is entirely driven by a shift in the supply curve (as previous authors suggest), we invoke facts five and six. Fringe followers price well below fringe preceders, implying that they are lower-cost producers. If HP's entry merely shifts the supply curve down, then it is not clear why fringe followers wait for HP to enter-a low-cost fringe firm could enter on its own and reap the resulting benefits. Further, the sales increase is so large that a shift in supply curve without a shift in demand (or change in demand elasticity) could only generate such an increase if the demand curve was already extraordinarily elastic.

\section{Conclusion}

This paper has sought to open a conversation on the dynamic processes by which a segmented industry evolves. To date, work on industry evolution has generally not dealt with this question. We propose that a dominant firm, faced with slowing growth in its current segment, will search for new segments in which to employ its resources. The new segments it chooses allow it to exploit its technological capabilities but avoid cannibalization of its product line. The low-cost dominant firm will introduce lower prices (and likely alter demand through its other assets such as brand image), which will, in turn, trigger a sales takeoff. Incumbent fringe firms that are well suited to compete in the absence of the dominant firm will exit the segment; new fringe firms who are well suited 
to compete in the shadow of the dominant firm will enter with or after the dominant firm. Thus, the entry of the dominant firm causes churn in the segment. As the market matures and growth slows in the segment, the process repeats itself.

Evidence from the desktop laser printer industry largely conforms to the predictions of this theory. Overall, we find that our seven theoretical predictions enjoy both descriptive and statistical corroboration. We believe that on the whole, this is a good outing and adds credibility to the idea that the theoretical insights of industry evolution can be extended to a segmented industry by incorporating theories of dominant firms that change industry structure and create churn.

That said, in this initial exploration, we raise nearly as many questions as we answer. Several are particularly relevant as areas for future research in strategic dynamics, particularly in the dynamics of segmented industries. First, is the dominant firm equivalent to a collection of fringe firms, or is it qualitatively distinct? Although we present evidence that suggests dominant firms are different, it is possible that the entry of a group of low-cost fringe firms into a segment could achieve the same results as the entry of a dominant firm. Further exploration of this issue can help us understand the extent to which the evolution of segment industries must involve integration of insights from the dominant firm literature.

Second, what characteristics of fringe firms are associated with preceding HP into a segment (and then exiting upon HP's entry) versus following HP? Our initial exploration finds differences in four characteristics related to firm size, firm scope, and patents. Further exploration of this can help us better understand the distinct patterns of fringe firm entry and exit evident in this study, and can more broadly help us to understand competitive interactions among fringe firms.

Finally, this study suggests two avenues for further research that draw on other literatures. Our empirical test bed has had a single dominant firm throughout our sample period. This enabled us to cleanly identify the behavior of this firm and its effect on segmented markets. However, in many industries, the dominant firm changes over time as one firm eclipses another (Henderson and Clark 1990, Christensen 1997). Such competition for dominance will likely influence the entry and pricing behavior of these firms. Integrating work on dynamics of innovation with industry evolution in a segmented industry will likely be a productive avenue for future research. Relatedly, prior work has found entry and exit rates to be highly correlated (Dunne et al. 1988). Yet other literatures note an asymmetry around industry "shocks" whereby firms that precede the shock exhibit different exit rates than firms that enter after the shock (Agarwal et al. 2002,
Nickerson and Silverman 2003, Utterback and Suarez 1995). We find both correlation between entry and exit rates post-HP entry, and also an asymmetry between who exits and enters. More detailed elucidation of these patterns should be a fruitful endeavor for scholars to pursue.

\section{Electronic Companion}

An electronic companion to this paper is available as part of the online version that can be found at http:// mansci.journal.informs.org/.

\section{Acknowledgments}

The authors thank Jeongsik Lee for excellent research assistance. They also thank Joel Baum, Glenn Carroll, Bruno Cassiman, Ken Corts, Javier Gimeno, Takashi Hikino, Ig Horstmann, Marvin Lieberman, Peter Roberts, Ammon Salter, and seminar participants at the Academy of Management meetings, the DRUID Summer Conference 2006, the Mitsubishi Bank Foundation Management Conference, Carnegie Mellon University, Columbia University, INSEAD, National University Singapore, University of California at Los Angeles, Université de Paris, Washington University in St. Louis, and The Wharton School of Management for extremely helpful comments. The second author thanks the Social Sciences and Humanities Research Council of Canada for financial support. An earlier version of this paper was titled, "Lateral Dominance and Fringe Benefits: Strategic Dynamics Among Dominant and Fringe Firms."

\section{References}

Agarwal, R., B. Bayus. 2002. The market evolution and take-off of product innovations. Management Sci. 48(8) 1024-1041.

Agarwal, R., M. Gort. 2002. Products and firm life cycles and the determinants of firm survival. Amer. Econom. Rev. 92(2) 184-190.

Agarwal, R., M. B. Sarkar, R. Echambadi. 2002. The conditioning effect of time on firm survival: An industry life cycle approach. Acad. Management J. 45(5) 971-994.

Aldrich, H. E., C. M. Fiol. 1994. Fools rush in? The institutional context of industry creation. Acad. Management Rev. 19(4) 645-670.

Anderson, P., M. L. Tushman. 1990. Technological discontinuities and dominant designs: A cyclical model of technological change. Admin. Sci. Quart. 35(4) 604-633.

Bass, F. 1980. The relationship between diffusion rates, experience curves, and demand elasticities for consumer durable technological innovations. J. Bus. 53(2) S51-S67.

Brander, J. A., J. Eaton. 1984. Product line rivalry. Amer. Econom. Rev. 74(3) 323-334.

Caves, R. E., M. Fortunato, P. Ghemawat. 1984. The decline of dominant firms, 1905-1929. Quart. J. Econom. 99(3) 523-546.

Christensen, C. M. 1997. The Innovator's Dilemma. HBS Press, Boston, MA.

Consumer Reports. 2005. Consumer Reports Buying Guide. Consumers Union, Yonkers, NY.

de Figueiredo, J. M., M. K. Kyle. 2005. Product launch decisions by dominant and fringe firms. Acad. Management Best Paper Proc., Technology and Innovation Management Division, Honolulu, HI.

de Figueiredo, J. M., M. K. Kyle. 2006. Surviving the gales of creative destruction: The determinants of product turnover. Strategic Management J. 27(3) 241-264. 
Desai, P. S. 2001. Quality segmentation in spatial markets: When does cannibalization affect product line design? Marketing Sci. 20(3) 265-283.

Dunne, T., M. J. Roberts, L. Samuelson. 1988. Patterns of firm entry and exit in U.S. manufacturing industries. Rand J. Econom. 19(4) 495-515.

Gaskins, D. W. 1971. Dynamic limit pricing: Optimal pricing under threat of entry. J. Econom. Theory 3(3) 306-322.

Goldner, P. N., G. J. Tellis. 1997. Will it ever fly? Modelling the takeoff of really new consumer durables. Management Sci. 16(3) 256-270.

Goolsbee, A., C. Syverson. 2005. How do incumbents respond to the threat of entry? Evidence from the major airlines. Working Paper 11072, National Bureau of Economic Research, Cambridge, MA.

Gort, M., S. Klepper. 1982. Time paths in the diffusion of product innovations. Econom. J. 92(367) 630-653.

Hannan, M. T., J. Freeman. 1989. Organizational Ecology. Harvard University Press, Cambridge, MA.

Haveman, H. A. 1993. Follow the leader: Mimetic isomorphism and entry into new markets. Admin. Sci. Quart. 38(4) 593-627.

Helfat, C. E., M. B. Lieberman. 2002. The birth of capabilities: Market entry and the importance of pre-history. Indust. Corporate Change 11(4) 725-760.

Henderson, R. M., K. B. Clark. 1990. Architectural innovation: The reconfiguration of existing product technologies and failure of established firms. Admin. Sci. Quart. 35(1) 9-30.

Jovanovic, B., G. M. MacDonald. 1994. The life cycle of a competitive industry. J. Political Econom. 102(2) 322-347.

Judd, K. L. 1985. Credible spatial preemption. Rand J. Econom. 16(2) 153-166.

Kamien, M. I., N. L. Schwartz. 1971. Limit pricing and uncertain entry. Econometrica 39(3) 441-454.

Katz, M. L. 1984. Firm-specific differentiation and competition among multiproduct firms. J. Bus. 57(1) 149-166.

Klepper, S. 1996. Entry, exit, growth, and innovation over the product life cycle. Amer. Econom. Rev. 86(3) 562-583.
Klepper, S. 2002. Firm survival and evolution of oligopoly. Rand J. Econom. 33(1) 37-61.

Klepper, S., K. Simons. 2000. Dominance by birthright: Entry of prior radio producers and competitive ramifications in the U.S. television receiver industry. Strategic Management J. 21(10/11) 997-1016.

Mitchell, W. 1989. Whether and when? Probability and timing of incumbents' entry into emerging industrial subfields. Admin. Sci. Quart. 34(2) 208-230.

Moorthy, K. S. 1984. Market segmentation, self-selection and product line design. Marketing Sci. 3(4) 288-307.

Nickerson, J. A., B. S. Silverman. 2003. Why firms want to organize efficiently and what keeps them from doing so: Inappropriate governance, performance, and adaptation in a deregulated industry. Admin. Sci. Quart. 48(3) 433-465.

Saloner, G., A. Shepard, J. Podolny. 2001. Strategic Management. Wiley, New York.

Silverman, B. S. 1999. Technological resources and the direction of corporate diversification: Toward an integration of the resource-based view and transaction cost economics. Management Sci. 45(8) 1109-1124.

Stoneman, P., N. Ireland. 1983. The role of supply factors in the diffusion of new process technologies. Econom. J. 93(369a) 66-78.

Utterback, J., F. Suarez. 1995. Dominant designs and the survival of firms. Strategic Management J. 16(6) 415-430.

Wernerfelt, B., C. A. Montgomery. 1988. Tobin's $q$ and the importance of focus in firm performance. Amer. Econom. Rev. 78(1) 246-250.

White, A. 1981. The dominant firm structure: Theoretical myth or empirical reality? Southern Econom. J. 48(2) 427-436.

Yamawaki, H. 1985. Dominant firm pricing and fringe expansion: The case of the U.S. iron and steel industry, 1907-1930. Rev. Econom. Statist. 67(3) 429-437. 